\title{
The rôle of botany in the development of the Republic of South Africa with special emphasis on the contributions of the Botanical Research Institute
}

\author{
Being the papers delivered at a symposium held on 1st May 1978 on the occasion of \\ the 75th anniversary of the Botanical Research Institute
}

\section{VARIOUS AUTHORS}

\section{ABSTRACT}

Five papers cover different aspects of the contributions to and rôle of botany in the development of the Republic of South Africa. Two papers sum up the contributions for the non-agricultural and agricultural sectors.

The introductory paper by D. J. B. Killick provides a short historical account of the Botanical Research Institute, followed by a discussion of the contributions of the Institute to botany in South Africa through its National Herbarium and identification service as well as researches in taxonomy, plant anatomy, cyto-genetics, ecology, economic botany and data processing.

B. de Winter emphasizes the fundamental rôle of taxonomy and bio-systematics for planning and the optimal use of the natural plant resources. The current support for taxonomy and biosystematics is examined and proposals made for improving progress in the Flora of Southern Africa series.

For plant physiology, N. Grobbelaar discusses, firstly, the ways whereby the productivity of a plant species with its characteristic genetic constitution can be raised by determining and modifying for optimal response the effects of environmental factors such as spacing, mineral nutrition, water provision, etc.; and, secondly, usually when the first means has been achieved, of improving plant productivity by altering the genetic constitution of the plant so that it can perform better than its ancestors under the prevailing conditions.

After discussing and illustrating the applications and rôles of plant ecology, D. Edwards concludes that basic plant ecological research is required, firstly, at the regional level through regional plant ecological studies to supply the essential local knowledge needed by researchers, planners and users of the land; and, secondly, at the more detailed level where knowledge is needed of the processes and factors that govern the behaviour of vegetation so that it can be properly used, managed and manipulated.

M. J. Wells discusses the rôle of economic botanists for priority research assessment, and for research on problem plants, such as weeds, and on plants for food and other useful products, especially from the rich and untapped South African flora of over 17000 species. The needs for an adequate base of primary botanical data are stressed, and for ethnobotanical work to assist exploration of plant uses.

S. A. Hulme, in his summing up for the agricultural sector, points out that despite the emergence of the specialist agricultural disciplines, botanical research remains fundamental to the understanding of the plant. Following on the important contributions that botany has made to agriculture, there remain many important contributions to agriculture for the future through physiological and other botanical studies.

In his summing up for the non-agricultural sector, D. M. Joubert illustrates the ways whereby the influence of the Botanical Research Institute and its co-operation with other institutes and organizations extends beyond the purely agricultural field to other national programmes involving terrestrial and inland water ecosystems, in plant alkaloid research, in nature conservation, etc.

\section{RESUME}

DU ROLE DE LA BOTANIQUE DANS LE DÉVELOPPEMENT DE LA RÉPUBLIQUE D'AFRIQUE DU SUD, EN SOULIGNANT PARTICULIEREMENT LES CONTRIBUTIONS APPORTEES PAR L'INSTITUT DE RECHERCHE BOTANIQUE

Cinq articles couvrent les divers aspects des contributions apportées par la botanique au développement de la République d'Afrique du Sud et du rôle qu'elle y joue. Deux articles présentent un résumé des contributions dues aux secteurs non-agricoles et agricole.

Dans un article préliminaire, D. J. B. Killick retrace brièvement l'histoire de l'Inst itut de Recherche Botanique et discute son apport à la botanique en Afrique du Sud, par l'intermédiaire tant de l'Herbier National et du service d'identification que des recherches dans divers domaines: taxonomie, anatomie végétale, cytogénétique, écologie, botanique économique et traitement des données.

$B$. de Winter souligne le rôle fondamental de la taxonomie et de la biosystématique dans la planification et l'optimisation de l'usage des ressources végétales naturelles. Le soutien que rencontrent actuellement la taxonomie et la biosystématique est examiné et des propositions sont faites en vue d'assurer un meilleur progrès de la publication sérielle consacrée à la "Flora of Southern Africa".

Dans la domaine de la physiologie végétale, $N$. Grobbelaar discute d'abord les moyens d'augmenter la productivité d'une espèce végétale avec ses constituants génétiques propres, en déterminant et en modifiant pour obtenir une réaction optimale les effets de facteurs de milieu tels que l'espacement, la nutrition minérale, l'approvisionnement en eau, etc. Ensuite (habituellement quand le premier but a été atteint) sont examinés les moyens d'améliorer la productivité des plantes en modifiant leur constitution génétique de manière à obtenir une performance supérieure à celle de leurs ancêtres, dans les conditions régnantes.

Après avoir discuté et illustré les applications et fonctions de l'écologie végétale, D. Edwards en conclut que la recherche fondamentale sur ce sujet est nécessaire, premièrement au niveau régional par des études écologiques destinées à fournir les connaissances locales essentielles dont ont besoin les chercheurs, les planificateurs et les utilisateurs de la terre; et, deuxiemement, à un niveau plus détaillé auquel il est nécessaire de connaître les processus et les facteurs qui dirigent le comportement de la végétation de manière à pouvoir l'utiliser, le diriger et le manipuler convenablement.

M. J. Wells discute le róle de la botanique économique pour évaluer les priorités en matière de recherche ainsi que pour la recherche sur des plantes à problemes, telles que les mauvaises herbes, et sur les plantes alimentaires ou autrement utiles, en particulier dans la liste considérable et encore inexploitée d'une flore sud-africaine qui comprend plus de 17000 espèces. On souligne la nécessité d'une base adéquate de données botaniques primaires et d'un travail ethnobotanique qui aide la recherche sur les usages des plantes. 
S. A. Hulme, dans son résumé concernant le secteur agricole, souligne la fait que nonobstant la naissance des disciplines agronomiques spécialisées, la recherche botanique reste fondamentale pour la compréhension de la plante. Pour faire suite aux contributions importantes que la botanique a apportées à l'agriculture, il en reste beaucoup à apporter dans l'avenir par l'intermédiaire des études de physiologie et autres branches de la botanique.

Résumant la situation pour le secteur non-agricole, D. M. Joubert illustre les voies par lesquelles l'influence de l'Institut de Recherche Botanique et sa collaboration avec d'autres instituts et organisations s'étend au-delà du domaine purement agricole à d'autres programmes nationaux intéressant les écosystèmes terrestres et d'eau douce, la recherche sur les alcaloîdes des plantes, la conservation de la nature, etc.

\section{The contribution of the Botanical Research Institute to botany in South Africa}

\section{J. B. KILLICK*}

As we are today celebrating the 75th anniversary of the Botanical Research Institute, it is perhaps appropriate that I commence my talk with a brief historical account of the Institute. This account will also serve as a background to the subject of my address and to those of the succeeding speakers.

The Botanical Research Institute dates its origin from the appointment in 1903 of Dr Joseph Burtt Davy as botanist and agronomist in the Transvaal Department of Agriculture. His first duties were to make extensive journeys throughout the Transvaal and to meet farmers, discuss agricultural needs and to collect and preserve specimens of the indigenous flora. The last-named function formed the beginning of the National Herbarium. Burtt Davy's office was in the old Volkstem Building, which still stands to-day on the corner of Pretorius Street and Fountain Lane. In 1905 he was joined by a plant pathologist, Dr I. B. Pole Evans, and shortly afterwards Miss Sydney Stent was appointed assistant to Burtt Davy and Dr Ethel Doidge as assistant to Pole Evans. Research in crops and plant diseases was undertaken mainly at the experimental grounds at Skinner's Court in Pretoria West, the site of the present golf course.

When Burtt Davy retired in 1913, Pole Evans became head of the combined Division of Botany and Plant Pathology in the Union Department of Agriculture. Dr Pole Evans was a short, but dynamic Welshman, who indeed proved to be a "man of destiny" as once predicted by Dr E. P. Phillips. About this time the Division moved to Vrede Huis at the foot of the Union Buildings. At this site a room $12 \times 5$ metres was erected to house the herbarium collection. Two notable appointments in these early days were Miss M. D. Gunn, who later became librarian, and Miss I. C. Verdoorn, who later became taxonomist.

In July 1918, at Pole Evans's instigation, the Minister of Agriculture approved the creation of a Botanical Survey Advisory Committee, comprised of leading botanists from the four provinces "to carry out and supervise a botanical survey of the territories included in the Union". The stated aims of the Committee make interesting reading to-day: fourteen in number, they are sound in principle and wideranging in scope covering such disciplines as plant taxonomy, ecology, geography, physiology, pathology, pasture science and economic botany. An important decision of the Committee was to publish the results of surveys in a series to be known as the Memoirs of the Botanical Survey of South Africa. Following the Memoirs in 1921 were Bothalia, a Deputy Director, Botanical Research Institute, Department
of Agricultural Technical Services, Private Bag X101, Pretoria, 0001 . medium chiefly for taxonomic papers and the Flowering Plants of Africa, an illustrated serial much on the lines of the well-known Curtis's Botanical Magazine.

The first wing of a new herbarium, of which Dr E. P. Phillips was curator, was opened in 1923 by General J. C. Smuts. About this time a valuable link with European botany was established when a post of liaison officer at the Herbarium of the Royal Botanic Gardens, Kew, was created.

Under the energetic leadership of Pole Evans, the Division expanded rapidly. A plant physiology unit was started at Fauresmith Veld Reserve under Dr Marguerite Henrici, the Natal Herbarium was acquired and the maintenance of the museum herbaria in Grahamstown and Kimberley were agreed to. Thus, regional herbaria came into being. The National Herbarium meanwhile benefited from the incorporation of the important collections of Galpin, Marloth, Pegler, Flanagan, Dieterlen, Thode and others.

Eventually a Division of Plant Industry was formed, comprising the sections botany, plant pathology, horticulture, entomology, field husbandry and pasture research. It is difficult to believe that much of what is to-day the Department of Agricultural Technical Services was once a single Division under the direction of a botanist! However, when Pole Evans retired in 1939 the sections again became separate divisions with Dr E. P. Phillips as head of the Division of Botany and Plant Pathology.

Dr R. A. Dyer succeeded Dr Phillips in 1944 and, after relative dormancy during World War II, development again proceeded apace. Negotiations with the Faculty of Agriculture of the University of Pretoria led to the establishment of the Pretoria National Botanic Garden. In 1956 the Trustees of the Transvaal Museum donated the valuable Museum herbarium to the Division. In the same year, with the final retirement of Dr Henrici, physiological work at Fauresmith ceased and the Veld Reserve was transferred to the O.F.S. Region. Similarly, the Veld Reserve at Worcester, where Karoo fodder plants were studied, passed to the Winter Rainfall Region.

Changes in the name of the Division occurred from time to time. In 1953 Plant Pathology hived off, leaving Botany on its own. In 1961, with the reorganization of the Department, the Division was renamed the Botanical Research Institute. About the same time the herbarium of the University of Stellenbosch's Botany Department was added to the regional herbaria of the Institute. In 1963 Dr L. E. Codd became director of the Institute.

Following a full-scale Public Service Commission inspection in 1966, additional posts were allocated to the Institute and four sections were recognized, namely the Herbarium Service and Information 
Section, a separate Flora Research Section, the Botanical Survey Section and the Economic Botany Section. Continued progress followed culminating in the opening of this building in July 1973. A few months later, Dr Codd retired and was succeeded by the present Director, Dr B. de Winter. A fifth section, the Data Processing Section, was created in 1976. This, then, is the history of the Institute in broad outline.

Now we can consider the contributions made by the Institute to botany in South Africa. First of all, let us consider the National Herbarium, Pretoria, and the regional herbaria. The National Herbarium, with its c. 500000 specimens is the main repository for plant specimens in the Republic. It, together with the regional herbaria, identifies some 32000 specimens annually for a variety of institutions etc., for example Onderstepoort, the Agricultural Regions, our own Botanical Survey Section, the Forestry Department, the Provincial Nature Conservation departments, the universities, farmers and the general public, as well as institutions in neighbouring countries such as Swaziland, Lesotho and Botswana. It is clear that a considerable number of research projects in southern Africa have relied and are relying heavily on the identification services provided by the Institute. Let me cite a few examples: nearly all the identifications for Dr A. Jacot Guillarmod's Flora of Lesotho were done by the National Herbarium; similarly, Professor Compton's Check-list of Swaziland, Palmer \& Pitman's Trees of Southern Africa, Professor van der Schijff's survey of the Kruger National Park and Professor N. Grobbelaar's study of nitrogen-fixing plants. I wonder whether we fully appreciate this identification service; it is a facility not enjoyed in many countries.

Herbaria do not just grow and expand without deliberate input of specimens. Apart from the specimens gained from ecological surveys, the Institute has undertaken numerous collecting expeditions all over the Republic, South West Africa, Lesotho and even as far north as Kenya. The East African expedition was undertaken in 1938 by Pole Evans, an ardent collector and skilled photographer of vegetation.

Closely linked with the herbarium is taxonomic research: the herbarium houses the specimens studied by the taxonomist. A list of some of the taxa revised by taxonomists of the Botanical Research Institute will give some idea of the contributions to botany in this field: the Stapelieae, succulent Euphorbieae, Encephalartos and Cyrtanthus by Dr R. A. Dyer, Gladiolus (with Dr G. J. Lewis) and Ornithogalum by Mrs A. A. Mauve, Kniphofia and Plectranthus by Dr L. E. Codd, Zantedeschia by Dr C. Forssman, Crinum by Dr I. C. Verdoorn, Aristida, Stipagrostis and Eragrostis by Dr B. de Winter, the African species of Acacia by Dr J. H. Ross, and Crassula by Dr H. R. Tölken. In addition, there is the considerable research that has gone into the preparation of the several volumes of the Flora of Southern Africa, the two editions of Phillips's Genera and the first edition of Dyer's Genera. We are indeed fortunate to have an up-to-date Genera and an ongoing Flora. I do not wish to "knock" Australia, but that country has neither a Genera nor a recent Flora in spite of being blessed with nearly 100 plant taxonomists. An extremely important contribution to botany and agriculture in South Africa was Lucy Chippindall's "Guide to the identification of the grasses" in the "Grasses and pastures of South Africa" (1955).
So far I have only spoken of flowering plant taxonomy, but in years gone by the Institute has also accomplished much in mycology, for example the revisions of fungi by Dr E. M. Doidge (author of the monumental, 1004-page "South African fungi and lichens to the end of 1945"), Miss A. M. Bottomley, Dr P. H. B. Talbot and their successors.

Associated with taxonomic research is the Anatomy and Cyto-genetics Laboratory. Although only 10 years old, it has already proved its worth. The survey of the leaf and embryo anatomy of the South African grasses, with its standardized descriptive schedules and computer linkage, is a model piece of research, which is yielding interesting results and will undoubtedly assist in taxonomic studies of the grasses. The cyto-genetic studies of the Eragrostis curvula complex, Lantana camara, Opuntia aurantiaca etc. are similarly yielding useful results.

The Botanical Survey Section of the Institute has contributed many important surveys of vegetation in this country. A look at the 42 Memoirs of the Botanical Survey of South Africa (mostly ecological) published by the Institute will give one a good idea of the scope and quality of the surveys carried out. One immediately thinks of the surveys of Albany, Keiskammahoek, the southern Kalahari, the Tugela Basin, the Cathedral Peak area of the Natal Drakensberg, to name only a few. However, undoubtedly the most significant survey undertaken was Acocks's "Veld Types". The resultant memoir, together with the vegetation map, has proved to be a classic work much quoted by scientists of many disciplines. The particular virtue of the map is that besides being a vegetation map, it is also a land-use map. It is true to say, I think, that very few countries possess a comparable map, and I believe that the U.S.A. only recently decided to produce such a map.

The Institute has frequently taken the lead in quantitative ecology in the Republic: first of all by applying association analysis, then ordination, and finally the Braun-Blanquet method. To gain expertise in the Braun-Blanquet method the Institute imported two specialists from the Netherlands, Dr M. .J Werger and Mr F. van der Meulen, and the result is that the method has become standard practice in the survey repertoire of the Botanical Survey Section. By means of workshops the method has been introduced to other institutions.

The Botanical Survey Section is intimately involved in the South African Savanna Ecosystem Project at Nylsvley and in various conservation projects, e.g. the survey by Dr D. Edwards to determine the adequacy of conserved areas in relation to vegetation types, and the survey of the Zululand coastal dunes by Dr P. Weisser to establish conservation priorities as the result of dune mining.

The Economic Botany Section is a comparatively new section of the Institute, but many of its functions have been carried out from the very beginning of the Institute. You will remember that in the account of the history of the Institute, I mentioned that among Burtt Davy's duties was a study of forage plants, poisonous plants and weeds. The Institute has played its part in the introduction of pasture plants, e.g. kikuyu (Pennisetum clandestinum), teff (Eragrostis abyssinica), Sudan grass (Sorghum sudanense), Napier fodder (Pennisetum purpureum), Nile grass (Acroceras macrum) and Cocksfoot (Dactylis glomerata), to name only a few. As regards poisonous plants, we have always co-operated successfully with the 
Toxicology Section of Onderstepoort, and at present the Institute has an authoritative book on poisonous plants in the press, which should prove a useful reference work. We have played our part in weed identification, and Botanical Survey Memoir 37 is devoted to "Common weeds in South Africa". Also, we are presently involved in the study of important weeds such as Stipa trichotoma (Nassella tussock), Hakea species, Opuntia aurantiaca (Jointed cactus), Lantana camara, Salvinia molesta (Kariba weed) and Eichhornia crassipes (water hyacinth). Taxonomic, cytogenetical, autecological, physiological and other approaches are being adopted. The Economic Botany Section has in past years become deeply involved in survival work in co-operation with the Department of Defence. The Section has collaborated with the United States Department of Agriculture in its cancer survey: staff of the Economic Botany Section have collected plant material, which is screened in the U.S.A. for anti-tumour activity. Now, bulk collections are being made of promising species that are undergoing clinical trials.

The Data Processing Section is the youngest section of the Institute. Its main task to date has been the computerization of the National Herbarium. All 500000 specimens have been encoded and processed, and programmes for the retrieval of herbarium information are nearing completion. In computerizing the National Herbarium, the Institute has achieved a first in South Africa, and a first in the world for large herbaria.

Mention must be made of the Mary Gunn Library. In building up what is virtually a national botanical library, the Institute has provided South African botany with a priceless asset-one that is used by botanists all over the country and even across our borders. Credit for this library must largely go to Miss Gunn who, by perseverance and persuasion, built up the library from scratch.

Since 1926 the Institute has had a Liaison Officer at Kew. This has proved invaluable to the Institute and South African botany. Six of our staff here to-day, including the Director and one past director, have had spells at Kew and profited immensely from the ex- perience. Apart from the training received and contacts made with European botanists, the liaison officers have solved many taxonomic and nomenclatural problems submitted to them by the Institute and universities.

The Pretoria National Botanic Garden is a garden with a difference. Catering for only indigenous plants, it provides research workers with study material, it serves as a plant introduction centre, and at the same time it provides the public with an attractive recreational and educational amenity.

The end-product or culmination of most research is the scientific publication. The Institute, as already mentioned, publishes Bothalia which has now reached Vol. 12, No. 3, Memoirs of the Botanical Survey of South Africa, No. 42, Flowering Plants of Africa, Vol. 44, and the Flora of Southern Africa, six volumes. Much of the significant research in taxonomy and ecology in South Africa has been published in these works. For an Institute of our size to publish two journals with an international reputation, a prestige serial and a Flora is an achievement. Besides its own publications, the Institute has contributed substantially to a number of authoritative botanical and related works, for example "Wild Flowers of the Transvaal" (Letty), "Trees of Southern Africa" (Palmer \& Pitman), "Ericas in Southern Africa" (Baker \& Oliver) "Aloes of South Africa" (Reynolds), "Grasses and pastures of South Africa" (Meredith), "The medicinal and poisonous plants of Southern Africa" (Watt \& Breyer-Brandwijk), several books on South African wild flowers and gardening by Sima Eliovson and the recently-published "Biogeography and ecology of Southern Africa" (ed. Werger).

In conclusion, may I say that it has been impossible in the time at my disposal to describe all the contributions of the Botanical Research Institute, but I hope that what I have said will have convinced you that the Institute's contributions to South African botany have been considerable. In fact, ladies and gentlemen, I would go so far as to suggest, in all modesty, that the Institute's contributions have constituted the major part of South African botany in the fields mentioned. We shall continue to achieve

\section{Die bydrae van taksonomie en biosistematiek in die ontwikkeling van Suid-Afrika}

\section{B. DE WINTER*}

Nomina si nescis perit et cognitio rerum-as die name verontagsaam word sal ook die kennis van dinge vergaan. In hierdie sinsnede het Linnaeus (Stafleu, 1971), die vader van die moderne biologie, die "rasionale", die logiese grond, vir taksonomiese navorsing opgesom. Hierdie eenvoudige woorde is vandag nog net so waar as wat hulle twee honderd jaar gelede was, of oor twee honderd jaar in die toekoms sal wees. Sonder name wat wetenskaplik gebaseer is, kan oordrag van kennis op 'n suiwer basis nie geskied nie.

Naamgewing is 'n aktiwiteit wat eng verbonde is aan die proses van klassifikasie, waaroor Hopwood (1955) soos volg wysgerig opmerk; "The urge to classify is a

- Direkteur, Navorsingsinstituut vir Plantkunde, Departement van Landbou-tegniese Dienste, Privaatsak X101, Pretoria, 0001 . fundamental human instinct; like the predisposition to sin, it accompanies us into the world at birth and stays with us to the end." Soos naamgewing die fondament is waarop die ontsluiting van kennis oor dinge berus, is klassifikasie die fondament vir 'n rasionele proses van naamgewing.

Hierdie twee prosesse, naamgewing en klassifikasie, vorm die hoekstene van die algemene sistematiek en dus ook vir die plantsistematiek. Die plantsistematiek verskaf die raamwerk waarin kennis oor plante op 'n betekenisvolle manier gestoor word, terwyl die name van die taksa (plantgroepe van enige rang) die sleutels tot die literatuur en dus die opgegaarde kennis van alle plante is. Hieruit volg dat die sistematiek die fondament van die biologiese wetenskappe vorm, en waar hierdie fondament gebrekkig is, sal alles wat daarop gebou word dus noodwendig ook gebrekkig wees. Vir hierdie stelling is die ontwikkeling van die 
moderne genetika een van die sprekendste voorbeelde. Die genetika vind sy fondament in die raamwerk van verwantskappe van organismes soos weerspieël deur die taksonomiese klassifikasie. Die klassifikasie van die grasfamilie het byvoorbeeld die basiese gegewens verskaf waarop telingswerk met graansoorte soos koring gebaseer is. Hierdie klassifikasie, bevestig en ondersteun deur genetiese navorsing, is verfyn en uitgebrei deur biosistematiese navorsing wat die weg gebaan het vir meer gesofistikeerde telingswerk. Vir die voorkoming van epidemiese siektes, wat deesdaags meer dikwels begin voorkom onder monokulture van gewasse, is taksonomie onontbeerlik, aangesien dit inligting oor die primitiewe teelmateriaal-nodig vir die teling van nuwe siekte-bestande kultivars-moet verskaf. Aangesien die moderne tegnokrasie afhanklik is van die beskikbaarheid van voldoende voedsel en energie, speel die taksonomie saam met die genetika dus ' $n$ fundamentele rol in die onderskraging van ons samelewing.

Ten spyte van die ooglopende belang van die taksonomie word die rol van hierdie wetenskap oor die algemeen geweldig onderskat en die studie daarvan verwaarloos. Verskeie redes kan hiervoor aangevoer word. Een van die belangrikstes is die wydverspreide pseudo-wetenskaplike opvatting dat taksonomie dikwels so subjektief beoefen word dat dit nie as 'n wetenskap beskou kan word nie. Persone wat hierdie opinie toegedaan is, toon min begrip van die fundamentele gegewens neergelê in taksonomiese sisteme wat die produk is van die gesamentlike vernuf van generasies van taksonome, en bevestig is deur toetsing van die resultate aan die bevindings van anderssoortige biologiese navorsing. Terwyl ek 'n diep respek het vir die eksperimentele basis van die wetenskap, aanvaar ek ook dat die menslike brein waardevolle dinge kan voortbring, wat nie alleenlik berus op die interpretasie van eksperimente nie. 'n Ander wydverspreide wanopvatting aangaande die taksonomie is die totaal ongegronde aanvaarding deur baie leke en selfs wetenskaplikes dat biologiese organismes of alreeds tot in die fynste besonderhede, of ten minste voldoende, geklassifiseer en van name voorsien is. Hierdie opvatting word waarskynlik in die hand gewerk deur die effektiewe uitgebreide gratis plantbenamingsdiens wat hierdie Instituut verskaf, waardeur die indruk geskep word dat Floras vir uitkenning van plantsoorte oorbodig is. Indien hierdie diens opgeskort sou word sal daar gou besef word hoe noodsaaklik dit is om verbeterde middels om plante te benaam te ontwikkel.

Hierbenewens sal 'n ontleding van projekte onderneem in wetenskaplike instellings in Suid-Afrika sonder twyfel uitwys dat daar dikwels min of geen ag geslaan word nie op die verkry van betroubare benamings van plante gebruik in eksperimente.

Heelwat gepubliseerde navorsingsresultate oor plante is verder nie die papier werd waarop hulle gedruk is nie, omdat hulle nie deur verwysingseksemplare gerugstaaf is nie. Selfs onder wetenskaplikes bestaan dus ' $n$ gebrek aan kennis en insig oor die rol en belangrikheid van plantsistematiek, en is dit waarskynlik deels hieraan te wyte dat in Suid-Afrika onvoldoende ondersteuning vir die taksonomie gegee word. In kontras hiermee is daar 'n toenemende wêrtld wye besef van die uiters waardevolle bydrae en fundamentele belangrikheid van hierdie wetenskap. Dit blyk uit, onder andere, die resolusies wat deur twee onlangse internasionale kongresse aan die regerings van alle lande van die wêreld gerig was. Ek haal enkele frases aan uit die resolusies van die IUBS Kongres, gehou in
Noorweë in 1973 en bevestig op die Internasionale Botaniese Kongres in Leningrad in 1975. Hulle lui soos volg:

"The International Union of Biological Sciences, Recognising that the future of mankind depends on the treatment given to natural resources and that a rich variety of living organisms is a fundamental part thereof,

Recognising that our present knowledge is very deficient and that in most biological disciplines, and especially in ecology, a proper knowledge of the systematics of the investigated organisms is of decisive importance,

Realising that the biotica of many countries are still imperfectly known, that taxonomic handbooks are lacking for many organisms and areas, and that competent taxonomists are too few to cope with all the material that requires determination,

Urges all governments, especially those providing technical assistance to developing countries, to strengthen taxonomy and especially taxonomic infrastructure required for training taxonomists and for making the ecological studies necessary to facilitate improvements in the use of resources and the effectiveness of technical development."

Hierdie resolusies is vandag reeds oorbekend. Nogtans is sedert 1973 min vordering gemaak met die regstelling van die leemtes in ons organisasies en ons is nie in ' $n$ veel sterker posisie om die taksonomiese probleme die hoof te bied as vyf jaar gelede nie.

Die prentjie wat geskilder is, het egter ook 'n meer rooskleurige sy. Die groot vooruitgang wat gemaak is op die breë gebied van plantkunde sedert 1905 en die rol wat hierdie instituut daarin gespeel het, is reeds deur Killick (1979) uiteengesit. Die huidige stand van sake op taksonomiese gebied kan kortliks soos volg opgesom word.

1. 'n Uitstekende fisiese infrastruktuur vir uitgebreide alfa-taxonomiese navorsing bestaan reeds maar sal verder uitgebou moet word: die land beskik oor voldoende herbaria wat uitgebreide versamelings van goeie kwaliteit vir taksonomiese navorsing huisves; 'n netwerk van nasional: botaniese tuine bestaan reeds waarin inheemse plante aangekweek kan word as materiaal vir studie. Daar bestaan in meeste gevalle nog steeds voldoende stande van natuurlike plantegroei waarin populasiestudies van indiwiduele soorte onderneem kan word. (In die Winterreëngebied is die situasie reeds in baie opsigte kritiek en is baie soorte reeds bedreig.)

2. Goed ontwikkelde inligtings- en benamingsfasiliteite bestaan reeds maar het verdere ontwikkeling nodig: die Nasionale Herbarium en sy Streeksherbariums lewer 'n landswye inligtings- sowel as benamingsdiens, terwyl die Compton Herbarium, Kaapstad, en sommige universiteitsherbariums ook 'n bydrae maak; die Databank vir herbarium- en taksonomiese inligting wat ontwikkel word deur die Navorsingsinstituut vir Plantkunde, sal binnekort in werkende orde wees en die dienste grootliks verbeter.

3. Die voorbereiding van die Flora van Suidelike Afrika word onderneem deur 'n span van vyf taksonome in die Navorsingsinstituut vir Plantkunde. Ondersteuning met die voorbereiding word ontvang van samewerkers in die universiteite en in ander navorsingsinrigtings, sowel as van 'n aantal oorsese wetenskaplikes. Ses volumes of dele van die beoogde drie-en-dertig volumes oor blomplante is reeds voltooi en met 'n verdere vyf word goeie vordering 
gemaak. Een volume het in die reeks vir Kriptogame verskyn en 'n volume oor die mosse is in voorbereiding.

4. Taksonomiese navorsing word verder ondersteun deur 'n laboratorium vir anatomiese en genetiese navorsing in die Navorsingsinstituut vir Plantkunde en deur morfologiese studies aan die Universiteit Pretoria en verskillende ander universiteite.

5. Die grootste probleem wat ondervind word in die beskikbaarstelling van taksonomiese kennis is die gebrek aan goed opgeleide mannekrag en aan voldoende fondse.

6. Die gebrek aan mannekrag kan hoofsaaklik toegeskryf word aan: die gebrek aan voldoende poste vir taksonome; die gebrek aan dinamiese en inspirerende opleiding in taksonomie aan baie universiteite; die relatief lae besoldigingsstruktuur vir die taksonoom in die staatsdiens ('n faktor wat die taksonomie in gemeen het met baie ander wetenskappe); die beeld van die taksonomie wat nie as een van die huidige "modevakke" soos molekulêre biologie, gesien word nie; die tans nog onderontwikkelde fasiliteite en geleenthede vir biosistematiese studies wat uit die alfa-taksonomie moet groei en wat die meer aantreklike studieveld vir die jonger taksonome daarstel.

In die voorafgaande is die huidige stand en die probleme van die taksonomie in Suid-Afrika kortliks geskets. Sal dit met hierdie struktuur moontlik wees om aan die eise wat in die toekoms aan ons gestel gaan word, te voldoen? Ek meen dat die antwoord hierop negatief is.

Die geweldige druk wat vandag op die natuurlike omgewing uitgeoefen word, veral as gevolg van die ongeëwenaarde bevolkingsaanwas en die tegnologiese ontwikkeling waarmee gepoog word om die nodige voedsel, behuising en ander behoeftes te bevredig, het 'n gestadige agteruitgang van ons omgewing tot gevolg. Slegs deur 'n kennis van die ekologie van ons omgewing (d.w.s. van ekosisteme) op te bou, waarop optimale benutting geb"eer kan word, sal ons in staat wees om die pr ble le die hoof te bied. Die taksonomie is, soos rt d beklemtoon, die fondament waarop die ander vel ak ings van die plantkunde moet bou. Plantkundiges uit verskillende navorsingsrigtings wat in hulle werk yestrem word deur 'n gebrek aan noodsaaklike taksonomiese inligting, begin nou druk uitoefen om te verseker dat 'n deeglike taksonomiese basis so gou moontlik geskep word. Voorbeelde, onder andere, is die Weidingsvereniging van Suidelike Afrika, die Werkgroep vir Skaars en Bedreigde Plante en Diere, die Fynbosbioom-Projek sowel as natuurbewaringsinrigtings by wie daar 'n groeiende bewuswording van die belangrikheid van die plant en die habitat vir die dier te bespeur is.

Die probleem van uitkenning van die groot aantal plantsoorte wat voorkom in die Fynbos en die gebrek aan handboeke vir hul uitkenning en benaming, maak 'n floristiese klassifikasie van plantegroeitipes van 'n praktiese standpunt gesien tans feitlik onuitvoerbaar. Die opstelling van die "Flora van Suidelike Afrika" is verder geïdentifiseer as die prioriteitsprojek op plantkundige gebied deur die Advieskomitee vir Plantkundige Navorsing, wat deur die Minister van Landbou aangestel is. Dit is teen hierdie agtergrond dat die spoedige voltooiing van die Flora van Suidelike Afrika deur meeste deskundiges gesien word as noodsaaklik. Hierdie serie sal uit drie-en-dertig volumes bestaan wanneer die blomplante, wat slegs 'n deel van die plantegroepe verteenwoordig, beskrywe en geklassifiseer is. Slegs ses volumes of dele hiervan is tot dusver voltooi. Die bestaande span van vyf taksonome wat in hierdie Instituut met voorbereiding van die Flora besig is kan selfs met die hulp van lokale en oorsese samewerkers, die reusetaak om die ongeveer 17000 blomplantsoorte in die Republiek te klassifiseer en te boekstaaf, nie in 'n redelike tyd afhandel nie. Die Navorsingsinstituut vir Plantkunde het in die laatste paar jaar alles gedoen om die projek prakties en uitvoerbaar te maak. Die formaat van die werk is tot die minimum ingekort en kortpaaie is gesoek vir tydrowende praktyke. Wat ons betref is daar slegs een verdere tydbesparende prosedure wat nog uitgevoer kan word, naamlik die samestelling van 'n "meesterregister van plantname" wat die projek letterlik met verskeie manjare sou kan verkort.

In die voorafgaande is hoofsaaklik uitgewy oor die blomplante. Die laer plantgroepe moet egter nie uit die oog verloor word nie. Die bewerking van die mosse word tans deur slegs een kontraknavorser onderneem. Die ligene en lewermosse kry feitlik geen aandag nie, terwyl die alge sporadies en op 'n ongekoördineerde basis bestudeer word. Taksonomiese navorsing op die belangrike plantgroep, die fungi, wat 'n groot aantal ekonomies waardevolle sowel as patogene soorte bevat, is geheel en al onvoldoende. Hierdie onbevredigende situasie verdien ernstige aandag.

Om die blomplante binne 'n redelike tyd te kan afhandel is daar minstens vyf addisionele taksonome, ondersteun deur vyf tegniese assistente, nodig. Die totale addisionele koste hiervoor sal na beraming R60 000 per jaar beloop wat oor 'n periode van tien jaar beskikbaar gemaak sal moet word. Vir die koste van R600 000 - minder as een vyfde van die prys van een vegvliegtuig-kan die blomplante vir hierdie fundamentele werk in ongeveer tien jaar afgehandel word.

Die voltooiing van hierdie standaardwerk hou die volgende voordele vir die land in:

(a) Dit sal 'n afbakening en breë oorsig van alle blomplante in die land verskaf en naamveranderings in die toekoms beperk.

(b) Dit sal benaming van plantmateriaal baie vergemaklik, en meer betroubaar en goedkoper maak.

(c) Dit sal basiese plantkundige inligting vryelik beskikbaar maak.

(d) Dit sal die saamstelling van streeksfloras moontlik maak wat die taak van die ekoloë en ander navorsers baie sal vergemaklik.

(e) 'n Flora is 'n permanente bate wat deur hersiening in waarde toeneem.

Ten spyte van al hierdie oorwegings kry die "Flora" nie die soort ondersteuning wat dit sal omskep in 'n prakties uitvoerbare lewenskragtige projek nie. Wat is die redes hiervoor?

Navorsingsgebiede soos planttaksonomie en plantekologie, wat van fundamentele belang is in die beplanning van die land se biologiese hulpbronne word ondersteun in hierdie Instituut maar nie tot die mate dat dit sal voldoen aan die eise gestel deur ander navorsingsgebiede en beplanning van die omgewing nie. Hierdie fasette van plantkunde kompeteer moeilik met die prioriteite van die Departement van Landboutegniese Dienste waarvan voedselproduksie die belangrikste is. Fondse word nietemin elders vir biologiese projekte van dieselfde of laer prioriteit en 
dikwels van minder dringende aard, deur die Staat beskikbaar gemaak. Die Nylsvley Ekosisteemprojek, waaraan die Instituut ten volle deelneem, het byvoorbeeld in die laaste vyf jaar uitgegroei tot 'n nasionale biologiese poging wat jaarliks meer as R200 000 kos en soortgelyke projekte is besig om te ontwikkel. Hierdie projekte is afhanklik van taksonomiese gegewens maar ten spyte daarvan word taksonomiese en ekologiese studies in hierdie Instituut onvoldoende ondersteun. Hierdie voorbeelde is slegs aangehaal om aan te toon dat daar 'n gebrek aan realistiese bepaling van prioriteite in die nie-landboukundige biologiese veld bestaan. Die toenemende oorvleueling van navorsing deur verskillende organisasies en staatsdepartemente, die bestaan van talle navorsingspanne van subkritiese grootte en die onrealistiese en oneweredige verdeling van wetenskaplike manne$\mathrm{krag}$ is verdere simptome van 'n ongewenste situasie waarop ek kortliks wil ingaan.

Biologiese navorsing in Suid-Afrika word tans deur verskeie departemente en instansies onderneem. Daar bestaan egter geen liggaam wat biologiese navorsing op nasionale vlak koördineer en prioriteite kan bepaal nie. Totdat hierdie leemte gevul is, sal probleme steeds groter word en mettertyd aksie afdwing.

Persoonlik het ek geen twyfel nie dat 'n navorsingsraad vir nie-landboukundige biologiese navorsing nodig geword het. Die enigste alternatief hiervoor is volgens my mening 'n nasionale koördinerende advieskomitee wat op landswye basis aanbevelings sal kan maak oor die uitskakeling van onnodige oorvleueling, en wat moet besin oor prioriteite en die toewysing van staatsfondse vir biologiese navorsing.

Tot hiertoe het ek slegs die sogenaamde alfataksonomie behandel. Wat uiteengesit is, is slegs die lê van 'n goeie fondament. Die alfataksonomie moet opgevolg word deur biosistematiese studies. In sulke studies word dieper ingegaan op spesiale probleme en word gebruik gemaak van 'n breë spektrum van tegnieke soos genetika, anatomie, fisiologie, plantgeografie, chemo-taksonomie, en so meer. Hiermee is die instituut reeds besig en plante soos die ekonomies belangrike grassoort Eragrostis curvula en die gevaarlike onkruid Lantana camara word biosistematies ondersoek met die oog op ontwikkeling en kontrole van die twee plantsoorte. Hier kom die volle potensiaal van die basis gelê deur die taksonomie tot ontwikkeling. 'n Uitbreiding van die personeel van die anatomie- en genetika-laboratorium is noodsaaklik, veral met die oog op die haglike onkruidsituasie.

Die plantgeografie is ' $n$ aspek wat binne die volgende paar jaar sterk ontwikkel sal word aangesien die databank vir herbariumgegewens ons in staat sal stel om verspreidingskaarte op baie groot skaal beskikbaar te maak. Sulke kaarte is van groot praktiese belang vir weidings-, gifplant- en soortgelyke studies en kan lig werp op die oorsprong en ontwikkeling van ons plantegroei.

Daar sal in die volgende dekades ook aandag gegee moet word aan palinologiese studies met die oog op die ondersteuning van taksonomiese en forensiese navorsing, terwyl die taksonomie van fossiele plante uitgevoer in 'n plantkundige inrigting waar daar 'n intieme kennis van lewende plante beskikbaar is, hoogs wenslik is om die standaard van paleobotaniese navorsing te verbeter.

Die planttaksonomie het dus ' $n$ fundamentele en uiters belangrike bydrae om te maak in verband met die beplanning en optimale benutting van die natuurlike planthulpbronne van die Republiek. Met die oog op die relatief klein uitgawes wat die voltooiing van die flora moontlik sal maak, wil ek aanbeveel dat die Staat ernstig moet oorweeg om, as eerste stap, hierdie poging sterker te steun. Dit sal sonder twyfel tot groot voordeel van die Republiek wees om hierdie belegging te maak.

Nomina si nescis perit et cognitio rerum het Linnaeus twee eeue gelede gesê. Dit is nodig om in die toekoms hierdie waarheid in ag te neem by die bepaling van ons biologiese prioriteite.

\section{REFERENCES}

HopwooD, A. T., 1955. The development of pre-Linnaen taxonomy. Proc. Linn. Soc. Lond. 170: 230-234.

INTERNATIONAL BotaniCal Congress, 1975. Resolutions accepted at the closing plenary session of the XII International Botanical Congress 10th July 1975 in Leningrad. Taxon 24: 701-703.

KILliCK, D. J. B., 1979. The contribution of the Botanical Research Institute to botany in South Africa. Bothalia 12: 740-742.

Stafleu, F. A., 1971. Linnaeus and the Linnaeans. Utrecht: IAPT

\section{Die rol van plantfisiologie in die ontwikkeling van Suid-Afrika}

\section{N. GROBBELAAR*}

Ek neem aan dat ek gevra is om aan die verrigtinge deel te neem omdat ek toevallig tans die ere-president van die Suid-Afrikaanse Genootskap van Plantkundiges (S.A.G.P.) is en dit paslik is dat die Genootskap by hierdie blye geleentheid betrek word.

Hoe dit ookal sy, ek wil hierdie geleentheid gebruik om die S.A.G.P. se hartlike gelukwense an die Navorsingsinstituut vir Plantkunde op sy $75 \mathrm{e}$ verjaardag oor te dra.

In die ontwikkeling van verskeie aspekte van die Plantkunde in Suid-Afrika, het die Instituut 'n leidende rol gespeel en speel hy steeds 'n leidende rol. Ook in die stigting en latere ontwikkeling van die S.A.G.P.

* Professor, Departement Plantkunde, Universiteit van Pretoria, Hillcrest, 0083. self het die personeel van die Instituut 'n leidende rol gespeel. Die vroeëre Direkteur van die Instituut, Dr Codd, het trouens as voorsitter by die stigtingsvergadering van die S.A.G.P. opgetree en was daarna die S.A.G.P. se eerste president. Dr Bernard de Winter, die huidige Direkteur van die Instituut was die eerste sekretaris van die S.A.G.P. en sover ek weet dien hy sedert die stigting van die S.A.G.P. sonder onderbreking op die S.A.G.P. se Raad. Hy het ook al as die S.A.G.P. se Ere-president die Genootskap gedien.

Mag die Instituut nog lank bestaan en van krag tot krag gaan en in toenemende mate die geestelike tuist van al ons land se plantkundiges word.

Soos $\mathrm{u}$ weldra sal opmerk, verskil my praatjie heelwat van dié van die ander sprekers, deels omdat 
ek na my lof betuigings aan die Instituut, die Instituut ook ligtelik oor die vingers moet tik. My praatjie handel oor dic belangrikste afdeling van die plantkunde, naamlik oor die plantfisiologie. Dit is daardie onderdeel van plantkunde wat oor die lewensprosesse van plante handel-beide die chemiese en die fisiese lewensprosesse. Nieteenstaande die belangrikheid van die plantfisiologie figureer dit feitlik glad nie in die Navorsingsinstituut vir Plantkunde se werksaamhede nie. 'n Mens wil amper sê dat dit 'n skande is en dat die Instituut hierdeur nie sy naam waardig is nie.

Die beroemde Duitse wetenskaplike Justus Liebig het reeds in 1840 by die Britte gekla dat plantkundiges nie genoeg aandag aan die chemiese en fisiese aspekte van plante bestee nie. Hy het die haglike posisie onder andere toegeskryf aan die feit dat, soos hy dit gestel het: ..."... in Botany, the talent and labour of inquirers has been wholly spent in the examination of form and structure; chemistry and physics have not been allowed to sit in council upon the explanation of the most simple processes; their experience and their laws have not been employed, though they afford the most powerful means of help in the acquirement of true knowledge. They have not been used because their study has been neglected. All discoveries in physics and in chemistry, all explanations of chemists, must remain without fruit and useless, because, even to the great leaders in botany, carbonic acid, ammonia, acids, and bases, are sounds without meaning, words without sense, terms of an unknown language, which awaken no thoughts and no associations. They treat these sciences like the vulgar, who despise a foreign literature in exact proportion to their ignorance of it; since even when they have had some acqaintance with them, they have not understood their spirit and application."

Mnr die Voorsitter, dit is 'n kwaai aanklag maar gelukkig is dit darem nie werklik vandag meer geldig nie. Soos u weet is dit onredelik om te verwag dat die Instituut met sy beperkte mannekrag aan alle vertakkings van die plantkunde reg moet laat geskied en ons weet dat sy onaktiwiteit in die plantfisiologie nie werklik te wyte is aan onverskilligheid teenoor hierdie faset van die plantkunde nie. Die miskenning van die plantfisiologie binne die Navorsingsinstituut vir Plantkunde geniet op die oomblik die ernstige aandag van 'n Advieskomitee wat sy edele, die Minister van Landbou in die lewe geroep het. Moontlik lei die handelinge van daardie komitee nog tot die stigting van 'n nasionale laboratorium vir plantfisiologie binne die Navorsingsinstituut vir Plantkunde. Vorm en funksie vorm so 'n onvervreembare eenheid dat diegene wat dit bestudeer, slegs kan baat deur 'n intieme assosiasie met mekaar.

Omdat die plantfisiologie 'n baie fundamentele studieveld is, is dit meestal internasionaal van aard. In soverre Suid-Afrika egter sy eie spesifieke en soms unieke probleme besit sal sekere plantfisiologiese aspekte soos droogte bestandheid, 'n groter rol in die ontwikkeling van hierdie land as in die ontwikkeling van sekere ander lande speel. Suid-Afrika is verder geseën met 'n ryke verskeidenheid plantsoorte met uiteenlopende groeivorme en habitatvoorkeure waaruit daar met tyd ongetwyfeld 'n magdom ontdekkings gemaak sal word waarvan vele vir die mens tot groot nut mag wees. 'n Mens dink byvoorbeeld onwillekeurig aan die siektegenesende stowwe wat in sekere plante voorkom maar wat nog nie chemies geïsoleer en geïdentifiseer is nie.
Wanneer ons vra hoe plantfisiologie in die ontwikkeling van Suid-Afrika kan help, dan gaan dit primêr om die mens. Dit kom eintlik daarop neer dat ons vra: "Hoe kan Plantfisiologie help om Suid-Afrika 'n beter plek vir die mens te maak?"

Namate ons basiese kennis vermeerder sal 'n mens 'n langer lysie kan opstel as wat ek aan u gaan voorlê. Vir die huidige wil ek egter met 'n paar idees volstaan wat soms miskien baie idealisties mag klink. Teen die tempo waarteen die wetenskap vorder en met die vertroue wat ek in die kwaliteit van ons jeug het, aanvaar ek egter dat wat vandag haas onmoontlik lyk, weldra uitvoerbaar sal wees.

Sover ek kan sien sal Plantfisiologie in hoofsaak twee benaderings kan volg. In die een sal daar getrag word om 'n bestaande plantsoort, met sy kenmerkende genetiese samestelling, se produksie te verhoog deur die invloed van sulke omgewingsfaktore soos spasiëring, mineralevoeding, watervoorsiening, ens. op die plant te bepaal en op 'n praktiese wyse te optimaliseer. In die ander benadering, wat veral aangewend sal word as eersgenoemde benadering vervolmaak is, sal daar getrag word om die genetiese samestelling van die plant deur teling so te verander dat dit onder bestaande toestande beter as sy voorouers sal presteer.

In laasgenoemde benadering wat hoofsaaklik 'n genetiese benadering is, behoort die plantfisiologie dikwels ' $n$ baie belangrike rol te vervul deurdat dit groter spesifisiteit aan die teelprogram kan verleen en deurdat dit die tydrowende praktiese uittoetsing van die nuwe genetiese lyne kan vervang met vinnige toetse wat as maatstawwe van sukses gebruik kan word.

Vir sover dit die mens aangaan, is die vernaamste funksie van plante ongetwyfeld hul rol as primêre produseerders. Hierdie funksie is nou gekoppel aan hul vermoë om met behulp van sonligenergie talle organiese verbindings vanuit $\mathrm{CO}_{2}$, water en sekere mineralesoutione, deur middel van die proses van fotosintese te sintetiseer. Sodoende voorsien plante op 'n direkte en indirekte wyse voedsel aan die steeds toenemende bevolking. Sodoende vang die plant ook sonligenergie op en stel hy dit as potensiële chemiese energie ter beskikking van die mens. Die hout van bome is na uitdroging direk beskikbaar as soliede brandstof. In die geval van suikerryke plante kan 'n geskikte fermentasieproses gebruik word om etielalkohol uit die suiker te berei-afgesien van sy ander stimulerende funksies, is etielalkohol 'n uitstekende vloeibare brandstof.

Namate die fossiele brandstofreserwes met tyd afneem, sal ons in toenemende mate op die fotosintetiserende vermoë van plante aangewys wees as 'n bron van energie. Die fossiele brandstowwe word egter nie slegs as bron van energie gebruik nie. Steenkool en aardolie is die bron van 'n ryke verskeidenheid organiese stowwe wat in talle industrieë 'n onmisbare funksie vervul. Namate steenkool en aardolies minder vryelik beskikbaar word, sal alternatiewe bronne van hierdie stowwe gevind moet word. Dit lei by my geen twyfel dat in die verskeidenheid van plantsoorte wat elk duisende soorte organiese verbindings bevat, hierdie probleem te bowe gekom sal word nie. Die potensiaal van talle plantsoorte sal egter sistematies ondersoek moet word en waar nodig sal die plante veredel moet word.

As die primêre-produseerder-aspek van plante hul vernaamste bate vir die mens is, dan moet ons onsself 
afvra hoe ons onder Suid-Afrikaanse toestande die produksiepotensiaal van plante kan verhoog. Voordat ons dit sinvol kan probeer beantwoord moet ons egter eers weet wat die vernaamste beperkende faktore vir plantproduksie in Suid-Afrika is. Myns insiens is ' $n$ gebrek aan geskikte water verreweg die grootste beperkende faktor vir plantproduksie in Suid-Afrika.

Langs ons kuste het ons 'n oorvloed seewater. Aangesien sekere plantsoorte in baie brak water en in seewater kan leef, behoort dit moontlik te wees om ekonomies-waardevolle plantsoorte te teel wat veral langs die dorre weskus van Suid-Afrika deur middel van besproeiing vanuit die see suksesvol verbou kan word. In Israel word daar alreeds baie navorsing in dié verband gedoen maar ek is nie bewus van enige soortgelyke studies wat tans in Suid-Afrika aan die gang is nie.

Ons verloor jaarliks talle plante as gevolg van droogte. Dit geld veral vir ons kultuurgewasse. As hul voggehalte net effens daal hou hul op om te groei en sterf by verdere uitdroging. Dit moet hier beklemtoon word dat verwelking by mesofitiese plante hul fotosintese feitlik heeltemal stopsit en dat selfs as die plante weer turgessent raak, dit in baie gevall s dae neem voordat die plant weer normaal kan fotosintetiseer. In dié verband is dit belangrik om te besef dat vir baie soorte mesofitiese plante, die voggehalte van hul blare met minder as $1,6 \%$ hoef te daal vir die blare om vanaf ' $n$ turgessente na 'n verlepte toestand te verander. Kortom, 'n mesofitiese plantsoort moet feitlik deurgaans turgessent gehou word vir maksimale produksie en 'n kort tydelike watergebrek het 'n lang nadelige invloed op sy primêre produksie. Onder ons inheemse plantsoorte is daar egter verskeie spesies wat oor die vermoë beskik om lang periodes van intense uitdroging te oorleef. Dit behoort moontlik te wees om hierdie soort droogtebestandheid tot 'n mate by ekonomies-belangrike kultuurgewasse in te teel-veral nadat die fisiologie van die meganisme van sodanige droogtebestandheid ontrafel is.

Die inheemse plantsoorte van die droër streke van ons land beskik meestal oor waterbesparingsmeganismes. Oor die algemeen moet aktiefproduserende mesofitiese plante onder normale toestande geweldige groot hoeveelhede water tot hul beskikking hê vir die produksie van 'n relatief klein massa droë materiaal. Tog gebruik hierdie plante in werklikheid relatief min water. Die rede vir hierdie verskynsel is dat plante bedags as sonlig vir fotosintese beskikbaar is, $\mathrm{CO}_{2}$ vinnig vanuit die atmosfeer moet kan opneem. Dit geskied deurdat die huidmondjies van die blare in die lig oopgaan. Die oop huidmondjies maak dit egter ook moontlik vir waterdamp om vanuit die vogtige intersellulêre ruimtes in die blaar na die buite atmosfeer te diffundeer. Tensy die grootskaalse verlies van water deur wateropname vanuit die grond gekompenseer word, droog die plant uit en word sy produktiwiteit benadeel. Alhoewel transpirasie sekere voordele vir die plant inhou, is dit terloopse en nie-noodsaaklike voordele nie. Trouens, transpirasie moet as 'n onvermydelike euwel gesien word.

In die natuur vind ons dat verskillende plantsoorte oor 'n groot verskeidenheid van aanpassing beskik om transpirasie te onderdruk. In meeste gevalle maak die aanpassing egter 'n ernstige inbreuk op die produktiwiteit van die plant. So byvoorbeeld is die bladwisselende bome op die Transvaalse Hoëveld aangepas om jaarliks voor die aanvang van die gewone winterdroogte feitlik al hul blare te verloor. Sodoende word hul waterverlies drasties bekamp maar ongelukkig verloor die plante hierdeur terselfdertyd hul hele fotosintetiserende potensiaal tot tyd en wyl hulle weer in die lente nuwe blare vorm.

Een van die aanpassings $\left(\mathrm{C}_{4}\right.$ sindroom) onderdruk egter nie alleen waterverlies nie maar verhoog die plant se produksietempo. In hierdie geval beskik die plant oor ensieme wat ' $n$ veel groter affiniteit vir $\mathrm{CO}_{2}$ het as wat in ander spesies die geval is. Al verlaag die plant sy transpirasietempo bedags deur sy huidmondjies gedeeltelik te sluit, is die "trekkrag" vir $\mathrm{CO}_{2}$ so groot dat die $\mathrm{CO}_{2}$ dan nog teen 'n tempo die blaar binnedring wat feitlik gelyk is aan wat vir ander plantsoorte met volledige oop huidmondjies die gev: 1 sou wees.

Ek is van mening dat hierdie $\mathrm{C}_{4}$-geaardheid by ander plantsoorte as dié waarin dit reeds aanwesig is ingeteel kan word en dat die plante se produksiepotensiaal daardeur aansienlik verhoog sal kan word.

'n Ander interessante aanpassing teen transpirasie wat egter ten koste van fotosintese ontwikkel het, behoort, as dit saam met die $\mathrm{C}_{4}$-sindroom in 'n plant aanwesig is, sy produksiepotensiaal nog verder te verbeter en wie weet, moontlik sal dit nog in die toekoms bewerkstellig word. In hierdie geval, gaan die plant se huidmondjies snags, wanneer die neiging vir transpirasie laag is, oop. Die plant absorbeer dan 'n redelike maar beperkte hoeveelheid $\mathrm{CO}_{2}$ vanuit die buite-atmosfeer deur sy huidmondjies. Gedurende die dag wanneer die neiging vir transpirasie baie hoog is, sluit die huidmondjies en voorkom dit sodoende transpirasie feitlik heeltemal. Fotosintese, wat slegs in die lig kan plaasvind benut nou die $\mathrm{CO}_{2}$ wat tydens die nag ingeneem is. Aangesien die hoeveelheid $\mathrm{CO}_{2}$ wat snags opgegaar kan word veel minder is as die maksimum wat bedags deur fotosintese benut sou kon word as die huidmondjies oop sou wees, het hierdie plante wat meestal sukkulente is, 'n lae groeitempo maar is hulle relatief bestand teen verdroging.

Om transpirasie verder te bekamp maar fotosintese te stimuleer vereis 'n aanpassing wat, sover ek weet, nie by enige plantsoort aangetref word nie. Ek wil my egter verstout deur te voorspel dat die genetici van die toekoms nog so 'n aanpassing by plante sal induseer.

In hierdie aanpassing moet die fotosintetiserende organe van die landplant met 'n membraan omgewe word waardeur $\mathrm{CO}_{2}$ maklik kan diffundeer terwyl dit feitlik ondeurdringbaar vir watermolekule moet wees. Die membraan moet chlorenchiem omring wat die $\mathrm{C}_{4}$ tipe $\mathrm{CO}_{2}$-bindingsensieme bevat. Die dieperliggende weefsel moet oor die vermoë beskik om in die donker $\mathrm{CO}_{2}$ te bind en dit in die lig vir fotosintese beskikbaar te stel.

Deur die euwel van transpirasie bevredigend te onderdruk kan die tempo van fotosintese nie alleen verhoog word nie, die aanpassings soos bladwisselendheid, wat fotosintese tot slegs die nat deel van die jaar beperk, sou din uitgeteel kon word sodat ons selfs op die Hoëveld van die Transvaal 'n kouebestande immergroen en aktief-produserende plantegroei sou kon daarstel.

Naas water, is stikstof seker die algemeenste beperkende faktor in die produktiwiteit van plante in Suid-Afrika.

Alhoewel daar 'n ontsettende groot reserwe aan stikstof in die atmosfeer is, is daar relatief-gesproke net 'n handjievol bakterieë wat hierdie vorm van stikstof kan benut. Party van hulle, die Rhizobium bakteriee kan alleen stikstof bind as hulle in simbiose 
met 'n geskikte peulplant leef. Verskeie spanne navorsers in die buiteland is aktief besig om te probeer om die genetiese samestelling van grasse sodanig te wysig dat hulle op hul eie, instaat sal wees om stikstof te bind. Op dié stadium is die kanse op sukses baie klein maar ek is oortuig dat dit net ' $n$ kwessie van tyd sal wees voordat sukses behaal sal word.

Aangesien stikstofbinding direk of indirek van 'n sterk toevoer van fotosintetiese produkte (ATP, NADPH en $\mathrm{H}^{+}$, en organiese sure) afhanklik is, sou 'n mens verwag dat Rhizobium bakterieë in blaarknoppies eerder as wortelknoppies as stikstof- binders behoort te floreer. Die feit dat daar tot dusver nog in geen geval stikstofbinding in blare geinduseer kon word nie, moet seker aan die toksiese invloed van 'n hoë suurstofkonsentrasie op die nitrogenase-aktiwiteit toegeskryf word. Indien nitrogenase egter in blare geinduseer kan word en 'n wyse gevind kan word om die nitrogenase teen die suurstof wat tydens fotosintese geproduseer word te beskerm, sal dit 'n dramatiese deurbraak in biologiese stikstofbinding verteenwoordig wat 'n belangrike rol in die ontwikkeling van Suid-Afrika behoort te speel.

\section{The rôle of plant ecology in the development of South Africa}

\section{EDWARDS*}

In straightforward terms, plant ecology is concerned firstly with describing, measuring and classifying the structure of vegetation: how its constituent plant communities are made up and organized and can be classified, which are necessary first steps in their study; and, secondly, with studying the processes that account for how vegetation behaves, why it is there in accordance with particular sets of physical and animal environmental factors, including mancontrolled influences. As a biological field of study it draws from other biological and physical disciplines, such as plant physiology and taxonomy, mathematics and soil science, but it has also developed its own unique concepts, principles and methodology.

In relation to its rôle in the development of South Africa, it will be apparent that plant ecology is really concerned with two aspects: firstly, with analysing and assessing vegetation, as a resource amongst which animals and human populations exist and without which they cannot exist; and secondly, by explaining how that vegetation exists under different kinds of natural and man-controlled environment, can be ascertained how it will react to and can be manipulated for human needs. Plant ecology thus has a basic rôle for the assessment, planned use and management of the natural vegetation resources of the country. It will be obvious, too, that use of vegetation, as well as of other resources, cannot be seen without reference to the use of the other natural resources of the country, so that integrated, planned use of the national resources is necessary. As expressed by Walker (1977), "The objective of integrated resource planning is the optimum use of natural resources for the maximum benefit of the population. This implies taking into account all of the requirements people may have for these resources, and trading off contribution to the Gross National Product against legitimate demands for recreational facilities and for reserve supplies for future commodity needs." Though not a new idea, ecological principles should play an important part in land use planning, and in predicting and assessing the consequences of various forms of resource use and human activity.

Within the last 150 years, population numbers and their distribution, land use and socio-economic conditions, have undergone major changes in South

- Assistant Director, Botanical Research Institute, Department of Agricultural Technical Services, Private Bag X101, Pretoria, 0001.
Africa. In an ecological sense, landscapes have changed from the natural to the semi-natural and subnatural, and ultimately to the cultivated and urban where human influences and structures are dominant. That these changes will continue to occur at an even faster rate is clear from population estimates for the future. These indicate a doubling of the present population of some 25 million by the end of the century, with projections of more than 80 million people by the year 2020. Not only will this 2,6\% annual increase in population represent an increase in the number of persons requiring more food, services, facilities, products, housing, space, etc., but an increased demand also because the anticipated rise in the average standard of living will mean even greater demands for food and the rational planned use of land and natural resources.

Current land use in South Africa is shown by the following data (Verbeek 1976):
General land use
Agriculture...
Nature reserves.
Towns and cities.
State land.
Roads, railways and airports
Forestry.
Remainder....
Total area.
102500000 ha $(83,3 \%$
3300000 ha $(2,7 \%)$
1600000 ha $(1,3 \%)$
I 500000 ha $(1,2 \%)$
1100000 ha $(1,0 \%)$
1500000 ha $(1,2 \%)$
10500000 ha $(8,8 \%)$
122000000 ha.
Use of land for agriculture and forestry

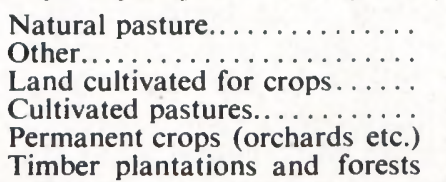
Total area.............. 102870000 ha.
83260000 ha $(81 \%)$
4150000 ha $(40 \%)$
12170000 ha $(11,8 \%)$ 930000 ha $(0,9 \%)$ 860000 ha $(0,9 \%)$
1490000 ha $(1,4 \%)$

Of the vast area of some 103 million ha available for farming, about two thirds, representing 55,5\% of South Africa, has a mean annual rainfall of less than $500 \mathrm{~mm}$. Agricultural intensification is thus limited by a low rainfall and the natural grazing provided by the indigenous vegetation is the major farming asset. However, it is also in these dry regions that the deterioration of vegetation and soils has been most widespread, resulting in desert and Karoo encroachment. While research to raise agricultural production is rightly being concentrated on areas with an inherently high agricultural potential, long term planning for optimum land use, increased production and reclamation of the drier regions cannot be ignored. 
For the remaining one third of the land available for agriculture where the mean annual rainfall is higher than $500 \mathrm{~mm}$, here, too, the natural vegetation has a rôle in farming since only some $15 \%$ of the land available to agriculture is estimated to be suitable for cultivation.

The conclusion to be drawn from the current land use data is thus that for natural pastures and nature reserves, amounting to $71 \%$ or 87 million ha of South Africa, the natural vegetation is the primary biological resource. To this should also be added a not inconsiderable amount of natural vegetation that needs to be managed for a variety of purposes, such as roads, railways and airport reserves, various state lands and miscellaneous areas. These amount to an additional nearly $10 \%$, or 13,1 million ha of South Africa. The natural vegetation is thus currently a major asset, requiring planned national use and for something like $80 \%$ at least of the surface of South Africa.

If one looks at future trends in land use, it is clear that while the area covered by natural vegetation may be expected to decrease, for over $55,5 \%$ at least of South Africa (67,7 million ha) the natural vegetation will still be the main agricultural resource because of climatic and other limitations, to which must also be added other unintensified agricultural land, nature reserves, road, railway and airport reserves (which can be expected to increase in amount), as well as miscellaneous other areas. It would seem not unreasonable to expect that between $55-65 \%$ of South Af ica's natural vegetation will still, in the foreseeable fature, provide an important source of agricultural produce, provide recreation and conservation environments, and provide the cheapest means of conserving soil and water. But an increase in population accompanied by technological innovation, the growth of urban complexes, and the intensified use of land will, as has been amply demonstrated during the past few decades, bring new problems for the maintenance of a stable and satisfactory human environment. Many of these problems can be anticipated and will need to be resolved by the application of ezological principles.

Because extensive pastoral farming obviously depends on the natural vegetation, much of the stimulus to early plant ecology in South Africa was provided by the need for basic ecological knowledge. The developing agricultural industry required knowledge of local ecological conditions and there were obvious problems arising from the use of the veld by the farmers. Naturally, there was also a strong scientific interest in the unique vegetation and flora. It was thus logical that in 1918 the South African government decided to appoint a Botanical Survey Advisory Committee, the majority of whose functions were to carry out basic and applied plant ecological research. In passing, it is refreshing to recall nowadays the comment in the Kew Bulletin of 1919 on "The enlightenment of outlook in matters connected with the bearing of scientific knowledge on practici 1 affairs which experience has taught us to expect on the part of the Government of the Union of South Africa ....".

The appointment of the Botanical Survey Advisory Committee was followed in 1925 by the appointment of the first Botanical Survey Officer ard by the creation in 1945 of an additional three posts for a small Botanical Survey Section specifically for basic plant ecological research in the Division of Botany and Plant Pathology, predecessor to the present
Botanical Research Institute. By this time the more specialized applied plant ecology concerned with what is now called pasture management was being actively developed by men such as Scott, Tidmarsh and West, who had originally been trained as botanists. Pasture management had become separated at university faculties and within the Department of Agricultural Technical Services. This pasture management research had expanded to the extent that in terms of personnel it exceeded basic plant ecological research. In this paper I would like to concentrate upon the rôle of basic plant ecology, rather than upon pasture management which has perhaps more clearly defined objectives and applications.

As set out in 14 points the aims and scope of the Botanical Survey Advisory Committee were remarkably clear and farsighted, reflecting the development of basic and applied plant ecology in South Africa and even the future organization of the present Department of Agricultural Technical Services.

The more specific plant ecological objectives agreed upon by the 1918 Botanical Survey Advisory Committee were:

(i) "To continue and extend the survey and systematic work already carried out.

(ii) "To continue and extend the work already accomplished by the Forest Department in further ascertaining the composition of the indigenous forests, the nature of their products and their industrial possibilities".

(iii) "To study the vegetation from an industrial point of view", which had implications for both applied plant ecology and economic botany.

(iv) "To study the plant succession under natural and artificial conditions"

(v) "To study the vegetation of the veld in connection with its feeding value and carrying capacity and to distinguish botanically between 'sour' and 'sweet' velds, good and bad pastures".

(vi) "To study the disturbing influence of burning, mowing, cultivation, drainage, irrigation, overstocking, insect and pest plants on the natural vegetation".

(vii) "To devote more attention to the soil and its micro-organisms", which anticipated the present Soils and Irrigation Research Institute and soil microbiological studies, and also the need for work on plant-soil interrelationships by plant ecologists and plant physiologists.

Following the establishment of the Botanical Survey of South Africa, basic plant ecological research has tended to concentrate on regional ecological studies. The early general accounts of the vegetation of South Africa by Bews, Pole Evans, Adamson, culminated in the now standard work on the Veld Types of South Africa by Acocks (1975), in which he recognized some 70 veld types and 70 variations. In detail and accuracy his 1:1500000 map was unique amongst national vegetation maps. Numerous regional studies were also carried out, the history of which is very largely reflected in the 42 volumes of the Botanical Survey Memoir series. Chiefly in the post war era, quantitative methods were applied to the measurement, classification and evaluation of vegetation. The use of computers and air photography has become standard practice, and satellite imagery has been investigated for its use in vegetation study and inventory, and for the regional assessment ecological factors such as fire. In the post war era there has also been an important endeavour to improve and standardise methods for efficiently classifying vegetation 
in a system that allows for prediction and extrapolation for subsequent study and for planning and management.

The main objectives of these regional studies have thus been to classify the various kinds of plant community and to establish their climatic soil and biotic relationships, as well as to ascertain the main functional processes, such as plant successional trends, and retrogressions leading to climax, sub-climax and disturbance kinds of vegetation. These studies supplied the basic knowledge needed to define the real problems requiring further basic and applied research on veld use, and provided assessments of the quality and kinds of vegetation resource upon which agricultural planning could be based.

In terms of the costs of such research it is worthwhile pointing out that such regional ecological studies, or surveys as they are commonly known, must surely rank as one of the cheapest forms of research. The application of cost-benefit analyses to such regional studies is difficult, however, because they serve an exceedingly wide range of direct and indirect interests for the current as well as the longterm periods of time. At best, an indication only can be given here of the rôle of such studies. They can be briefly illustrated for:

(i) Vegetation resource evaluation and planning.

(ii) Vegetation resource use and management, and

(iii) Research planning.

Vegetation resource evaluation and planning is done at two levels in agriculture: at farm planning level and at regional level. For farm planninggrazing camps, allocation of watering points, etc.ecological sub-divisions reflecting grazing potential and management needs have to be compatible with practical considerations such as fencing costs and overall farming objectives. Regional plant ecological studies showing the species content of plant communities, plant successional relationships, retrogressions and environmental indicators assist the agricultural extension officer and farmer to attain optimum land use potential by specifying what he has to farm and the farm's potential. Furthermore, by knowing and having classified the vegetation, intelligent extrapolation of the results of detailed grazing experimental work at agricultural research stations and from cooperative research projects on other farms, is possible. It is an important fact that regional plant ecological studies are currently lagging far behind because of the limited manpower and post allocation for such work. This has often resulted in the quite understandable but actual misapplication of broad scale ecological results from a national vegetation map such as Acocks to local farm planning.

At the regional planning level, regional plant ecological studies have assisted in locating agricultural research stations and in defining areas of high and low agricultural potential. Assessments have thus been possible for planning the many aspects of the agricultural industry.

For nature conservation, use of the national Veld Types map has been used to show areas requiring conservation-where ecosystems and gene pools of species are likely to disappear and which areas can serve as base line areas for future monitoring with respect to surrounding land use. Particularly striking, for example, was the fact that in 1974,42 of South Africa's 70 Veld Types had none or virtually no permanent conservation areas (Edwards, 1974). Planning of future nature conservation and recreation areas could thus be placed upon a more logical basis than before because of the national vegetation map. At local levels, the knowledge from regional plant ecological studies has assisted in road planning by indicating vegetation that should be conserved, as against that which is adequately conserved and not worth conserving. Regional planners have found that plant ecological studies can supply basic information relevant to development schemes, such as in the Saldanha Bay, Pretoria-Witwatersrand-Vereeniging complex, Eastern Transvaal, Natal and other areas. The allocation of roads and other development schemes can thus be undertaken without major conflict to environmentalists and to ecological principles obvious to an ecologist but not always to the non-ecologist.

For vegetation resource use and management, regional plant-ecological studies have, as already pointed out, served the farmer directly in farm management. Some of the most striking examples of the consequences of the misuse of land were defined by Acocks (1975). He described and mapped the secondary or False Karoo replacement of grassland for an area of $10 \%$ or 12 million ha of South Africa. Areawise, however, the conversion of extensive areas of grassland into less productive Karoo is far less than the deterioration of the Karoo itself, which covers nearly a third of South Africa, where the grass component has suffered more than in any other vegetation type in South Africa.

Plant ecologists have been amongst the first to point out other vegetational resource problems, such as the invasion of alien plants into the natural vegetation, and the increase of weedy and poisonous indigenous plants resulting from use of the veld. Attention has been focussed, too, upon aquatic weeds, which increase evapo-transpiration and impede recreational, agricultural and other use of dams and rivers.

Discerning the rôle of fire, the relationships to soil and climate and the effect of grazing and other forms of land use on the vegetation are an inherent part of regional plant ecological studies, which explain or at least present hypotheses to account for the different kinds of natural and man-induced plant community. Although the scientific method dictates that observations and hypotheses of cause and effect relationships should be subjected to the test of experiment, such experimentation needs intelligent planning for worthwhile objectives on a priority basis. Regional plant ecological studies thus provide information necessary to assess research priorities and the form that such research should take. For example, for the South African Savanna Ecosystem project at Nylsvley it may be argued on logical and legitimate grounds that in terms of extent, utilization problems and inherent potential, the savanna type ecosystem requires intensive study to elucidate the fundamental ecological processes governing that kind of ecosystem. Furthermore, since such multi-disciplinary research is expensive, it obviously requires careful planning and justification. Equally important too, is that proper extrapolation of the Nylsvley Project results will depend on the classification of vegetation resulting from regional ecological studies.

Although South African plant ecology has in the past been much concerned with the primary task of describing and assessing the nature of our vegetation, 
its ecological behaviour and characteristics, there has also been considerable research on autecological, eco-physiological and other studies of the basic processes that govern the behaviour of plant communities. One of the most remarkable series of studies was undoubtedly that carried out on ecophysiology by Dr Marguerite Henrici between 1922 and 1958. In over 70 scientific publications she examined a range of problems connected with agriculture, such as phosphorous deficiency and the water requirements of the natural veld. Other plant ecologists and pasture research workers have carried out experimental work to ascertain the effects of different kinds of burning, mowing and grazing management treatments of the veld.

As farming becomes more intensive and the overall pattern of land use also becomes more intense, the need increases for more exact information on the ecological processes regulating the behaviour of vegetation. The need for basic research is becoming more and more urgent on the eco-physiological processes regulating the behaviour of ecological systems, and for the ecologically important plants, weeds, rare and threatened species that make up these ecosystems. A consideration of the weed problem alone, that costs many millions of rands for their direct control, and many millions of rands for lost production from crops and livestock, indicates the justification for such research. Current work being carried out by this and other institutes on the growth and productivity of trees and grasses in the bushveld is leading to an understanding of the grass-tree relationship. Ultimately, better understanding of the scrub encroachment problem in South Africa will permit better and sustained use of the savanna type vegetation that covers about one third of the country.

Outside the field of agriculture, it is clear that there is developing a need for a new breed of ecologist, the applied ecologist, whose task is to manage and supply advice to other managers on how to maintain and regulate the various facets of the human environment. The management of areas such as marinas, water and terrestrial areas belonging to municipalities, game farms, etc., require trained ecological personnel. What is more, however, these applied ecologists will need an adequate background of basic local i.e. South African ecological research data to enable them to carry out their tasks. It seems more than likely too, as has happened in the United States, that construction and development agencies will require trained ecolo- gists to assess the environmental impact of development schemes. Government departments, the biggest employers of ecologists, at present have the services of ecologists, but to avoid carrying out advisory applied ecology work at the expense of their primary function as basic researchers, specialization amongst ecologists is becoming necessary. Research institutes at which there is a group of plant ecologists are in the fortunate position that when sufficient posts are available, the applied and advisory type ecologist has a background of basic research upon which he can call. Furthermore, by the feed-back process, much of the basic research needed can be appropriately problem orientated. The critical problem at present is the lack of sufficient posts to carry out the basic plant ecological programmes needed for the future and to provide for a body of applied advisory and management type plant ecologists.

To summarize and conclude, basic research is needed to satisfy a wide range of user requirements, now and for the future. This research is needed at two levels:

(a) At the regional level through regional plant ecological studies to supply the essential local information sorely needed by planners and users of the land, and for

(b) Research at the more detailed level where fundamental knowledge is needed of the processes that govern the behaviour of vegetation, so that it can be properly used, managed and manipulated for the common good.

Finally, the necessity for the translation of research data into practical terms for the user requires a special class of practical ecologist, who can ensure that plant ecology plays its rôle in ensuring the wise use of land in the future development of South Africa.

\section{REFERENCES}

Acocks, J. P. H., 1975. Veld types of South Africa. 2nd. ed. Mem. bot. Surv. S. Afr. No. 40.

Botanical Survey of the Union of South Africa., 1919. Kew Bull. 399-403.

Edwards, D., 1974. Survey to determine the adequacy of conserved areas in relation to vegetation types. A preliminary report. Koedoe 17: 3-38.

VerbeeK, W. A., 1976. Food and agriculture in South and Southern Africa. pp. 48-62 in Resources of Southern Africa-today and tomorrow. (ed.) G. Baker. Johannesburg: Associated Scientific and Technical Societies of South Africa.

WALKER, B. H., 1977. Towards a science of ecological management. Johannesburg: Witwatersrand University.

\section{The rôle of economic botany in the development of South Africa}

\section{J. WELLS*}

Botany should be seen not merely as the study of plants, but as the study of one of mankind's basic natural resources. It is the business of economic botany to increase the material benefits that man receives from plants, remembering not only man's need for foods, but also man's need for an environment with green growing things. Unfortunately, we are dealing not only with animal man and cognitive man, but also with unreasonable man, who wants to

- Chief Professional Officer, Botanical Research Institute, Department of Agricultural Technical Services, Private Bag $\mathrm{X} 101$, Pretoria, 0001 be free to breed and yet expects the quality of life never to diminish for himself and his children. For this reason good botanical economics will increasingly mean a good balance between plant utilization and conservation. Economic botanists have a definite rôle to play not only in utilization, but also in conservation: in respecting the conservation status of the plants that they seek to utilize; by giving tangible economic values to the indigenous flora; and by contributing to the control of weeds that threaten the flora.

If primary botanical data are lacking, then the rôle that the economic botanist can play is seriously 
restricted. At present, the main lack of basic information is: lack of information on the genetic make-up of problem taxa; the lack of, and patchiness of, distribution records for all plant species, but particularly for weeds; and the lack of a detailed or semidetailed vegetation map-coverage of the country as a whole.

If economic botanists have to collect this information for themselves, or do without it, their effectiveness will be greatly reduced. For example, without a detailed vegetation map it will be difficult to relate economic species and groups of species (such as weeds) to the communities in which they occur, and to land-use systems. For economic botany to play an optimal rôle in the development of South Africa, a national survey of vegetation resources to supply detailed vegetation and plant distribution maps should be completed as soon as possible.

Priority assessment in economic botany is difficult, because many of the factors determining priorities lie outside the field of botany. Not only are economic botanists seldom told what priorities agriculture and industry have for plant research, but they are often asked to provide these priorities for others. For example, economic botanists are constantly being asked "What are the most important weeds in South Africa?" The answer to this question depends largely on non-botanical considerations: the losses that weeds actually cause, and our ability to control them. However difficult it may be, botanists will have to accept more responsibility in priority assessment, and will have to broaden their knowledge of agriculture and other fields that relate to botany.

If they are to function efficiently in decision-making in the future, botanists will have to: foster the team concept that can draw together the expertise that is needed from related disciplines; initiate and build up data banks to enable the vast amount of relevant material to be gathered, stored, sorted and retrieved; and promote the co-ordination of decision making. Only in this way will research in economic botany be directed to the real priorities-and fulfil its real functions.

The choice of priorities has a special importance to those in economic botany since, if their work does not pay off, they are "uneconomic" botanists. When they choose a project, the profit and loss account is not restricted to the economic botanist, since a chain reaction is set in motion. The control of a weed or the establishment of a new crop, for instance, will ultimately involve a great deal of research input, labour and investment by agriculture and industry. For these reasons, the value of their work will be gauged not so much by its potential usefulness, but by the use that is actually made of it. This "evaluation in terms of usefulness' is currently being applied to the work that has been done on nassella tussock.

The threat posed by nassella tussock has been spelt out in no uncertain terms (Healy, 1978; Wells, 1976). We believe this to be a disaster plant of unequalled importance to this country. If unchecked, it could result in most of the best pasture land being covered with tussock. I think that the manner in which we deal with nassella tussock will be a fair test of this country's intelligence, ability and will to preserve its pastures as well as its flora. At the same time, in the eyes of many researchers it will be a test of the usefulness and the validity of botanical research on pasture weeds.
My assessment of the changing scene in South Africa, and how it is likely to affect the future work of economic botanists, is as follows (Wells, 1971). The greatest world-wide needs for plant products are for more food, f or more fuel, for new medicines, and for crops to replace sources of natural products that are either being exhausted (e.g. whale oil) or reaching their cultivation limits (e.g. timber for paper). Although all these are of concern, the most immediate concern is likely to be with the $r$ a ional need for local sources of energy and raw materials and to provide new crops for local use. Everything suggests that man's future plant food needs will be met mainly by improved breeding, selection and culture of established crop plants, rather than by some as yet undeveloped veld plant. Where established crop plants are concerned, economic botanists have a rôle to play, since there is a great need for research on the biological characteristics of the world's principal food plants (Thimann et al., 1966).

Africa has produced few major food plants, but three of these, grain sorghum (derived from several wild Sorghum species), pearl millet (Pennisetum americanum) and water-melon (Citrullus lanatus), are important in Southern Africa. Sorghum is probably one of the most important crops for the future since it is the cereal best adapted to regions with warm, dry climates. This characteristic is shared by pearl millet, which is the main crop in the sandy soils of Kavango and Ovambo. These could be the crops that will be needed for marginal agronomic areas and for this reason thorough botanical and genetic studies of Sorghum, Pennisetum and Citrullus should be undertaken.

Economic botanists also have a responsibility to collect material of primitive varieties of other crop plants grown by the local peoples. Preservation of these primitive cultivars is important for future crop breeding and development, and is urgent since they are likely to disappear as a result of the widespread monoculture of high-producing modern varieties.

Economic botanists must also contribute, through weed control studies, to primary food production. The extent of the contribution that can be made can be gauged from South Africa's average annual crop and pasture losses due to weeds which are estimated to be of the order of R600 million, equivalent to one-quarter of the total annual agricultural product. This estimate does not take into account the fact that agriculture does not stand alone, but is an integral part of the economic structure of the country, where industry handles agricultural products to the value of over R1 000 million every year (Anon, 1976).

The first task in weed research is to determine the occurrence, distribution and status of weeds. It is also obviously necessary to determine the weed groups, or complexes, that occur in association with particular crops and veld types, since without knowledge of these complexes, research and control aimed at individual weeds is likely to be inefficient.

Well known also is the countrywide deterioration of the veld, accompanied by replacement of natural dominants such as Themeda triandra and Digitaria species by hardier, less palatable "caretaker" plants such as Eragrostis spp., Sporobolus spp., Elionurus argenteus and Chrysocoma tenuifolia. These caretaker species are the new dominants of much of the veld (Acocks, 1971). In the past they have been regarded as weeds. The universal application of good pasture 
management, effective control over the utilization of the veld, could halt veld deterioration and justify concentrating research on optimal use of the best climax grasses. But, if the veld is allowed to continue to deteriorate, we would do well to forget about climax grasses and concentrate instead on the use and conservation of caretaker species.

Weed status studies need to be followed by periodic monitoring to provide early-warning of aggressive weeds and by intensive studies on priority species and complexes. Studies of a few priority weed species, such as Opuntia aurantiaca, Stipa trichotoma (nassella tussock), Lantana, and Australian Hakea and Acacia species, have been undertaken in recent years by the State research institutes and by researchers at universities. (Zimmermann et al., 1974; Wells, 1976; Stirton, 1978; Neser, 1974; van den Berg, 1977). These studies are providing for the first time sound background information on aspects such as genetic variability, environmental requirements, pollination, propagation and dispersal mechanisms highly relevant to the control of the species concerned. There is an urgent need for economic botanists to provide further intensive studies of weeds and weed groups. It is not suggested that more than a small part of the estimated R600 million presently lost to weeds, can be saved by this research, but even $1 \%$ represents R6 million, and it is certain that a great contribution to preventing further losses can be achieved by the early recognition and control of new weeds.

The need to produce more food will result in tremendous pressure on natural grazing lands, which cover $81 \%$ of the area of South Africa (Edwards, 1978). The definition of arable land will broaden to include many areas presently regarded as marginal for cultivation. Pressures on the remaining area will have a great effect on indigenous plant communities. Clearing and thinning of woody vegetation to increase herb growth and animal production, are likely to take place over most of the 30 million hectares of bushveld, representing about one-third of the natural pastures of South Africa. Radical veld improvement, amounting to veld replacement, is likely to take place as soon as suitable pasture legumes and grass mixtures are available. This replacement may be of the order of $10 \%$ of available land in the drier areas, and up to $75 \%$ of available land in the wetter areas, such as the foot-hills of the Drakensberg.

It is undoubtedly the duty of botanists to contribute to these changes coming about in an orderly and controlled manner. Contributions are already being made to two projects. Production studies in the bushveld or 'savanna eco-system' contribute to a knowledge of how best to manage this community whilst obtaining optimal grazing and browsing (Rutherford, 1978). A cytogenetic study of the Eragrostis curvula complex, which has resulted in eight fully sexual plants being found and brought into cultivation, has for the first time made controlled breeding for selected characteristics of this grass a possibility (Vorster \& Liebenberg, 1977). Such research on indigenous grasses and legumes needs to be expanded. New weed problems are certain to arise in the wake of ploughing marginal arable areas, and in areas where radical veld improvement is attempted. Veld replacement, a costly operation whose success depends on its permanence, is particularly vulnerable to weed problems. Woody invaders and tussock grasses such as nassella tussock, could find the conditions provided by attempts at veld improvement and replacement highly suitable for them. It is essential that the threat posed by these weeds, which are capable of causing agricultural disasters, should be removed so that agricultural options can remain open. Economic botanists will undoubtedly have important work to do on these weeds, and on indigenous veld species that become weeds in new situations.

Experience in other countries points to the fact that more and more indigenous plants will come to be regarded as weeds, as man tries to utilize more and more of the habitat which he shares with them (Reed, 1970). It will be the task of economic botanists to take the initiative in assessing the status of both indigenous and exotic weeds, and to help determine where and how research and control should take place. In the meantime, it is not necessary to carry out weed status surveys in order to know that certain weed problems demand attention. The invasion of the South African flora by Acacia spp., Eucalyptus spp., and Hakea species from Australia is proceeding unabated. Soon, unless very positive action is taken, these sometimes very useful Australian plants will have completely replaced the few remnants of lowland fynbos communities. As a matter of urgency, a report, similar to the nassella tussock report, must be produced, setting out the alternatives in unequivocal terms, the steps that must be taken in the light of existing knowledge, and the priority areas for research and control.

The search for new crops and replacement crops begins with South Africa's indigenous flora of 17000 species. Here the first responsibility is to preserve the available plant resources. Second is the need to preserve man's knowledge of this vegetation. With the advance of civilization, knowledge of folk uses of indigenous plants is rapidly disappearing. Economic botanists have a responsibility to collect and store the folk knowledge of indigenous peoples, and to use it in the search for new crops and products.

The hunt for new crops and replacement crops is closely linked to primary food production. South Africa has limited arable land, where the biggest challenge is to find new crops that do not compete for this space. Sugar is a valuable export crop, but it occupies vast areas that could be used for other food production. Sisal started life as a dry-area crop, but now competes with sugar and other food crops for a place in the wetter, higher production areas. More land is needed for afforestation in South Africa. At first only poor agricultural land was used for afforestation, but expansion is bringing forestry into competition with agriculture and with the need for catchment protection for water supplies. Sweeteners to replace cane sugar, and annual dryland paper crops to replace timber pulp, provide promising areas of research for economic botanists to help relieve crop competition pressures.

Plant utilization research can also make a direct contribution to conservation. Invasive Australian Acacia species, that threaten the flora, are still being planted as sandbinders, for lack of suitable indigenous replacements. This is seriously limiting the effectiveness of weed control, and there is an urgent need to explore the potentials of indigenous ground covers, sand-binders and barrier plants (Boucher \& Boucher, 1978).

At present industrial needs for replacement crops, for local sources of gums and other products, are handled on an ad hoc basis, and the small group of economic botanists available in the country is illequipped to cope with sudden demands for research 
of this kind. A systematic survey of strategic plant products should be carried out by industry, so that research priorities can be decided on, and so that economic botanists can plan how best to provide for the needs of industry.

It is likely that in the future industry will tend to employ its own economic botanists, but whether this will be on a sufficiently long term basis to provide job security in the profession remains to be seen. The solution to industries' needs may well lie with private firms carrying out work on a contract basis, with the state and the universities providing consultative services. This arrangement would also have the advantage of freeing state researchers to concentrate on studies, such as weed investigations and native uses of plants, that are beyond the scope and interest of private firms.

The development of economic botany in both the public and private sectors is not proceeding as rapidly as the needs of the country demand. There is a chronic shortage of economic botanists in South Africa. At present, although South Africa has one of the richest floras in the world and an almost untapped economic source, there are only a handful of researchers to work on its utilization. One of the most important tasks facing the small economic botany community in South Africa will be to provide university training to stimulate the supply of researchers to ranks of the profession. The rôle that economic botany can play will depend largely on the success of this venture.

Results, and the use of results, are extremely important to economic botany. This fits into the broader pattern in agriculture, where the utilization of results has never been more important and where it has in some cases become so crucial that research must take second place to extension. In botany there is undoubtedly a gap between research and extension and it will have to be bridged by research personnel fully able to interpret the results of their discipline and to ensure that research results do not lose validity in presentation and application. Even though there are many gaps in our knowledge of the 17000 indigenous plant species occurring in South Africa, botanists possess a great deal of knowledge about them that has not been used. Most of these species have been described and named. Their distribution and the conditions that seem to suit them are mostly known. It is possible, without leaving the herbarium, to

\section{Opsomming: Landbousektor}

\section{S. A. HULME*}

Ons is bevoorreg dat ons by hierdie geleentheid twee vorige direkteure, dr R. A. Dyer en dr L. E. Codd en die huidige direkteur, dr B. de Winter, persoonlik kan bedank vir hulle bydrae tot Plantkunde in SuidAfrika. Ons dank ook aan almal wat voor en saam met hulle was en is, vir hulle bydraes.

Mr Chairman, the germ that developed into the Botanical Research Institute originated in Pretoria in 1903 with the appointment of Dr Joseph Burtt

* Hoofdirekteur, Akkerbou en Weiding, Departement van Landbou-tegniese Dienste, Privaatsak 116, Pretoria, 0001 produce a preliminary assessment of many potentials of these plants, for example, their potentials as shade trees, hedges, ground covers and decorative subjects for different areas can be assessed. There is nothing to stop these things from being done except manpower, and a decision of priority.

The challenge before economic botanists is to make the best of the natural resources that are available. Relatively speaking, South Africans have been spoilt by the bounties of the veld. But in the future it will be the countries that can feed themselves and clothe themselves that will be strong and independent. Neither scientist nor layman can afford to neglect the plant-enemies or the productive plants that can contribute to our well-being.

\section{REFERENCES}

Acocks, J. P. H., 1971. The distribution of certain ecologically important grasses in South Africa. MS (unpublished).

ANON, 1976. Landbou in Suid-Afrika. 176 pp. Johannesburg: Chris van Rensburg Publikasies.

Boucher, C. \& Boucher, D. A., 1978. Uitheemse indringerplante bedreig die Kaapse weskus. Elsenburg Joernaal 2,1 $1-11$.

EDWARDS, D., 1979. The rôle of plant ecology in the development of South Africa. Bothalia 12: 748-751.

Healy, A. J., 1978. Nassella tussock in South Africa. 65 pp. Report (unpublished).

NeSER, S., 1974. Biological control of Hakea. In Report of First National Weeds Conference (unpublished). 55-57.

REED, C. F., 1970. Selected weeds of the United States. Agric. Handbook 366. 463 pp. Washington: U.S. Department of Agriculture.

RutherForD, M. C., 1978. Aboveground biomass subdivisions in woody specimens of the savanna ecosystem study area. (in press).

StIRTON, C., 1978. Tickberries on the march. Veld \& Flora 64: $8-11$

THIMANN, K. V. ET AL., 1966. The plant sciences now and in the coming decade. 100-114. Washington: National Academy of Science.

VAN DEN BEF G, M. A., 1977. Natural enemies of certain Acacia in Australia. In Proceedings of the Second National Weeds Conference, South Africa. 75-82. Cape Town: Balkema.

Vorster, T. B. \& LiebenberG, H., 1977. Cytogenetic studies in the Eragrostis curvula Complex. Bothalia 12: 215-221.

Wells, M. J., 1971. A study tour of the U.S.A.: economic botany-aims, functions and priorities. 87 pp. Report (unpublished).

WeLLS, M. J., 1976. Vordering met en wenke oor die beheer van nassella-polgras in die oostelike Kaap Provirsie. In $\mathbf{L}$. Lötter (Ed.), Boerderykeur. 46-51. Pretoria: Koöperasiepers.

ZimmermanN, H. G., Burger, W. A. \& Annecke, D. P., 1974. The biological control of jointed cactus in South Africa. In Report of First National Weeds Conference (unpublished). 204-211.
Davy in the Transvaal Department of Agriculture. In those days agriculturists were not trained in agricultural disciplines. Instead, they were trained as botanists or chemists and became crop scientists by adoption. As such the botanist was very much involved in the seedling stages of agricultural development in South Africa.

In later years, disciplines such as agronomy, horticulture, pasture science and plant pathology emerged. However, botany remained fundamental to the understanding of the plant itself, its vital processes, habits and habitats, as well as its relationships. 
Therefore, crop and pasture science, in striving for the solution of agricultural problems, still has to rely on principles developed by carrying on research deeply into basic botany.

Meneer die Voorsitter, gedurende die afgelope 75 jaar het hierdie Navorsingsinstituut vir Plantkunde belangrike bydraes gemaak om landbou-ontwikkeling in Suid-Afrika te ondersteun en te bevorder. Hierdie bydraes was egter merendeels nie die prestasies van afsonderlike indiwidue of seksies nie maar eerder die vrug van spanpogings in die Instituut. Ek wil enkele terreine waarin uiters belangrike basiese kundigheid gelewer is, as voorbeelde uitlig:

(i) Die ekologiese opnames van die Suid-Afrikaanse plantegroei vorm die grondslag vir die afbakening van veldtipes en die benutting van natuurlike veld.

(ii) Die identifikasie, verspreidingsopnames en autekologie van gifplante, sowel as van ander onkruide en indringerplante, dra by tot die doeltreffende bekamping daarvan in belang van die veebedryf en van landbouproduksie.

(iii) Die ontdekking van bruikbare hoedanighede van inheemse plante lei tot die benutting daarvan as voergewasse of andersins, soos in die geval byvoorbeeld van boegoe (Agathosma betulina), rooibostee (Aspalathus sr p.) en Proteas.

Tydens die teepouse het ons graansorghumbotterbroodjies met maroela- en kei-appelkonfyt of met jellie van stamvrug of van wilde druif geniet. Die tyd laat my nie toe om te verwys na die beskermingsmoontlikhede van plante met medisinale hoedanighede of na plante wat van belang is by oorlewingsaksies nie.

(iv) 'n Kennis van die plantegroei in al sy fasette, waarop optimale benutting gebaseer kan word, is noodsaaklik ten einde die agteruitgang van die omgewing te voorkom.

Hierdie onderskraging van landbou deur plantkunde is tot wederkerige voordeel. Daar vind kruisbestuiwing plaas. Dit gee aan plantkunde doelgerigtheid en lewenskragtigheid. Daardeur word voorkom

\section{Opsomming: Nie landbousektor}

\section{M. JOUBERT*}

Waar Plantkunde in Suid-Afrika ter sprake is gaan mens se gedagtes onwillekeurig terug na die vroeë ontdekkingsreisigers: Thunberg die Sweed, Masson die Skot, en ná hulle andermaal 'n Sweed en 'n Skot in die persone van Sparrman en Paterson. Want aanvanklik die unieke Kaapse flora, maar later ook die ewe interessante plantgemeenskappe verder noord, het onoortreflike geleentheid gebied aan persone met wetenskaplike aanvoeling om hul te versink in die botanie van die suidelike Afrika-vasteland. En ek glo dat ons almal alleenlik die hoogste waardering koester vir die noukeurige, mens wil amper sê "punteneurige" wyse waarop hulle te werk gegaan het om materiaal te versamel en te beskryf, en uiteindelik te bewaar saam met herbariummonsters uit al die uithoeke van die aardbol. Van meet af aan was hierdie prosedure vir ons voorbeelde van wetenskaplike eksaktheid wat die grondslag sou help lê van 'n eie Su.d-Afrikaanse

- Vise-President, Wetenskaplike en Nywerheidsnavorsingsraad, Posbus 395, Pretoria, 0001. dat plantkunde ontaard in bloot 'n akademies, teoretiese vakgebied wat nie die universiteitskampus kan verlaat nie.

Mr Chairman, the future rôle of botany for enhancement of improved food supply and stable agriculture will be even more important than in the past. In addition to the conventional means of improving crop production, we urgently need to advance our knowledge of photosynthesis, genetic manipulation, biological nitrogen fixation, uptake and utilization of moisture and nutrients as well as the biological stress (insects, diseases, nematodes and weeds), to establish principles to increase crop yields.

Green plants, as yet, are the primary harvesters of free solar energy. We need this energy as food, but as we are using up our fast-disappearing oil, natural gas and other fossil fuels we may have to turn from mining fuel to growing it. Yet, do we have sufficient knowledge of the bio-chemical events leading to carbon fixation and the processes of dark and photorespiration for improving photosynthetic productivity?

Mr Chairman, of all the numerous measures which contribute towards greater crop production the one at present showing best results is judicious fertilizer use. Yet, only 50 per cent of the nitrogen and less than a third of the phosphorus and potassium applied as fertilizer is recovered by crops. The balance is lost to the environment and meanwhile fertilizer prices are escalating.

With the energy use and capital costs of fertilizers we need to develop crops which are nearly nitrogen self-sufficiènt through symbiotic nitrogen fixation and seek micro-organisms for supplying nitrogen to cereals and grasses.

Meneer die Voorsitter, in die verlede het die resultate van plantkundige navorsing die landboubedryf onderskraag. In die toekoms sal selfs meer kundigheid van hulle verlang word om hulle bydrae te kan lewer. Daarom wens ons hierdie Instituut alle sukses toe vir die volgende 75 jaar en daarna.
Wetenskap-waarop ons nie slegs trots is nie, maar waarvan die Republiek toenemend afhanklik geword het.

Plantkunde het inderdaad sy amptelike beslag gekry in 'n landboukundige verband. Reeds in die April 1904-nommer van die Transvaal Agricultural Journal (slegs enkele maande dus ná die stigting van die herbarium wat moeder is van hierdie instituut) lees ons: "Mr Burtt Davy's Botanical Notes will prove of great value to farmers in helping them to identify the numerous troublesome weeds, economic grasses, poisonous plants and useful forage plants . . .' Maar in dieselfde uitgawe verskyn ook die eerste van etlike latere lyste van sowel populêre as wetenskaplike name van ons bekendste inheemse plante: doelgerigte pogings, dus, om belangstelling onder die leek in ons planterykdom aan te wakker, en meer besonder in die bome en struike van ons savanne-gebiede.

Hierdie bietjie geskiedenis bring my terstond by drie belangrike voortvloeisels uit die aktiwiteite van 'n 
lang opeenvolging van botaniste wat geopereer het vanuit wat ons vandag ken as die Nasionale Navorsingsinstituut vir Plantkunde (NIP): Allereerswaarvoor ek dan ook slegs die hoogste agting en waardering het-diens aan die Wetenskap per se soos blyk uit volgehoue betrokkenheid van agtereenvolgende Direkteure op elke moontlike terrein van die georganiseerde wetenskap hier te lande, te wete die voormelde J. Burtt Davy, I. B. Pole Evans, E. P. Phillips, R. A. Dyer, L. E. W. Codd en B. de Winter. Hierdie aktiewe belangstelling het onteenseglik bygedra tot die status van Suid-Afrikaanse plantkunde nie net hier te lande nie, maar ook in die internasionale wetenskaplike wêreld.

In die tweede plek sou dit 'n groot leemte laat indien die bevordering van botaniese kuns vergete bly. Onwillekeurig word gedink aan Cythna Letty, want sy het vanweë sowel haar uitmuntende talent as die lange duur van haar loopbaan 'n baie besonderse plek in hierdie terrein verower. Trouens na my oordeel bly Cythna Letty se Veldblomme van Transvaal een van die bes versorgde publikasies wat ooit in Suid-Afrika die lig gesien het. Maar, moontlik danksy die inspirasie wat van háár af uitgegaan het, was daar vele ander kunstenaars wat vir hulle roem verwerf het juis vanweë die voorreg om in die Instituut te kon werk en die vrugte van hul arbeid te kon publiseer in tydskrifte van die gehalte van, byvoorbeeld, Die Blomplante van Afrika en Bothalia.

Derdens, en dit is vir my eweneens van besondere betekenis, die stimulus wat van NIP af uitgegaan het aan, enersyds, persone om handboeke en handleidings te skryf wat, andersyds, die breë publiek se belangstelling in ons inheemse flora gaande sou maak. 'n Inventaris van sulke publikasies sal gewis lywig wees, maar persoonlik glo ek dat dr Codd se Bome en Struike van die Nasionale Krugerwildtuin spesiale vermelding regverdig, des te meer aangesien dit 'n produk van hierdie Instituut is.*

By this time it should be clear that the influence of the Botanical Research Institute (BRI) extends far beyond purely, or solely, agricultural application. To complete my summary I shall confine myself to examples of involvement and co-operation between this institution and the one which I happen to represent, namely the CSIR, since such examples may no doubt be extrapolated to testify of the experiences and sentiments of many other institutions also.

In the field of chemistry, when analysing products, the collection and correct identification of plants is extremely important. Thus in a project aimed at determining alkaloid concentrations in no less than 3000 plant species on behalf of an American pharmaceutical sponsor, the National Chemical Laboratory relied heavily on the closest of collaboration with the BRI. Likewise the investigations by the National Food Research Institute on the nutritive value of edible veld fruits have led to an exchange of expertise which is held in high regard by both parties concerned.

The National Institute for Water Research records numerous examples of co-operation ranging from the photographing of pollen grains by means of a scanning electron microscope and the making available to the BRI of limnological sampling apparatus, to their extensive use of the library facilities on the Brummeria

\footnotetext{
- Gaan dit nie 'n herdruk beleef nie? Die eksemplare tans nog in omloop het vandag groter versamelaars- as gebruikswaarde vanweë hul skaarsheid!
}

site. Clearly the most direct and uninterrupted collaboration with BRI, which also points to areas of undoubtedly common interest, stems from its participation in various Co-operative Scientific Programmes which are being co-ordinated by the CSIR. This includes seemingly trivial gestures such as the cataloguing and safe-storage of botanical material emanating from SASCAR's Marion Island involvement, as well as ostensibly highly sophisticated monitoring by means of remote sensing of the extent and occurrence of fire in the different veld types of South Africa, with particular reference to its ecological impact on veld management.

Maar hierdie skakeling strek veel verder: Binne die Nasionale Program vir Omgewingswetenskappe (NPOW) se Afdeling Binnelandse Waterekosisteme is daar onder meer verteenwoordiging vanuit die NIP in die Werkgroep vir Eutrofikasie. Insgelyks is daar samewerking oor en weer op die onderwerp van rietbeddens binne die vlei-ekosisteemprogram, asmede met die modellering van waterhiasinte op Hartebeespoortdam.

In die Afdeling Landbiologie van NPOW beklee die Instituut 'n sleutelrol in die Komitee vir Bedreigde Plante, 'n onderwerp waarmee reeds ver gevorder is. Ook is daar baie noue betrokkenheid in die Taakgroep oor Plantegroeiveranderings en die Werksessie oor Bioomtipes. Betreffende die Savanne-ekosisteemprojek is die NIP se personeel uiteraard ten nouste geintegreer by alle fasette met 'n enigsins botaniese strekking. En sodra die Fynbosbioomprojek op dreef is kan 'n gelykwaardige inset ook dáár verwag word. Daarbenewens verdien betrokkenheid by die Tweede Nasionale Onkruidkonferensie asmede die voormelde vuurekologie-oefening, spesiale beklemtoning in hierdie verband.

In die Nasionale Komitee vir Natuurbewaring (NAKOR) is die NIP se verteenwoordiging opsigtelik. 'n Betekenisvolle bydrae tot die Nasionale Plan vir Natuurbewaring het dan ook reeds hieruit voortgespruit.

Die Nasionale Instituut vir Vervoer- en Padnavorsing getuig van skakeling met NIP in verband met die beplanting van uitgrawings en opvullings, as teenmaatreël vir moontlike erosie. Ook word plante somtyds gebruik as aanwysers van die presiese ligging van geskikte padboumateriale, en die korrekte identifisering van sulke plante-met die hulp van NIP- is vanselfsprekend belangrik en trouens noodsaaklik.

Dit is dus 'n lang lys van raakvlakke, dog geensins volledig nie.

Ek het nagelaat om te verwys na die waardevolle diens wat direk vloei vanuit die Brummeria-kampus met betrekking tot openbare tuinuitleg en selfs die telkens milde verskaffing van geskikte plantemateriaal. Baie instansies kan getuig van sodanige dienste. Ook is te min gesê oor biblioteekuitruildienste; of oor NIP se betrokkenheid by die Suid-Afrikaanse Disseminasie van Inligting, die sogenaamde "SASDI-diens"; of oor die opname van NIP-geskrifte in die Suid-Afrikaanse Inligtingsentrum vir Water se bibliografiese databasis, bekend as WATERLIT, onder meer op die terrein van waterbesoedeling deur plantedoders.

Dit, dan, bring my by die einde van 'n uiters oppervlakkige samevatting. Niks is vermeld oor die vrugbare interaksie wat oor baie jare strek tussen die Navorsingsinstituut vir Plantkunde en Departemente van Plantkunde a an 15 Suid-Afrikaanse universiteite 
nie. Op sigself is dit ' $n$ breë onderwerp met talle voorbeelde van prysenswaardige samewerking, benewens blote hulpverlening vanaf die kant van die Instituut. My eerste kennismaking met die NIP was trouens van hierdie aard: bloot die identifisering van onbekende monsters van 'n onkruidversameling wat as taak moes dien vir Agronomie I. Op die oog af 'n geringe, moontlik lastige diens, maar toentertyd vir my absoluut onontbeerlik.

Vyf-en-sewentig jaar is verby en mens kan slegs wonder wat Burtt Davy se gewaarwordinge sou wees indien hy vandag saam met ons die pad kon opry: deur die kunstige hekke--inderdaad uitmuntende voorbeelde van die smeekuns - tot by hierdie pragtige gebou wat lank reeds 'n landmerk geword het op die sandsteenrantjie, geleë op 'n gedeelte van 'n gedeelte van die plaas Hartebeestpoort No 328, Transvaalwaar ons as kinders stamvrugte (Bequaertiodendron magalismontanum en mispels (Vangueria infausta) gesoek het, en ook soms aan 'n goudgeelryp wildeappelkoos (Landolphia capensis) kon smul.

Wat 'n trotse rekord vir hulle wat ons vooruit gegaan het en 'n inspirerende uitdaging vir geslagte wat sal kom! En op hierdie dag, saam met talle ander vriende en belangstellendes, my hartlike gelukwense asmede beste wense vir die toekoms.

\section{UTTREKSEL}

$V y f$ verskillende referate behandel verskillende aspekte van die bydraes tot, en die rol van plantkunde in die ontwikkeling van die Republiek van Suid-Afrika. Twee referate som die bydraes tot die nie-landboukundige en landboukundige sektore op.

Die inleidende referaat deur D. J. B. Killick is 'n kort geskiedkundige verslag oor die Navorsingsinstituut vir Plantkunde, gevolg deur 'n bespreking van die Institu't se bydraes tot plantkunde in Suid-Afrika deur sy Nasionale Herbarium en benamingsdiens sowel as navorsing op planttaksonomie, plantanatomie, sitogenetika, ekologie, ekonomiese plantkunde en dataverwerking.

B. de Winter beklemtoon die fundamentele rol van taksonomie en biosistematiek in beplanning en optimale benutting van natuurlike planthulpbronne. Die huidige ondersteuning van taksonomie en biosistematiek word ondersoek en voorstelle word gemaak om vordering met die Flora of Southern Africa-reeks te versnel.
Vir plantfisiologie bespreek N. Grobbelaar eerstens die maniere waarop die produktiwiteit van ' $n$ plantsoort met sy eie kenmerkende genetiese samestelling verhoog kan word deur die uitwerking van omgewingsfaktore soos spasiëring, minerale voeding, watervorsiening ens. vas te stel en te modifiseer vir optimale reaksie. Tweedens word die maniere bespreek om, gewoonlik nadat die eerste doelstelling bereik is, plantproduktiviteit te verhoog deur die genetiese samestelling van die plant so te verander dat dit beter as sy voorgangers kan presteer onder die heersende toestande.

Nadat hy die toepassings en rol van plantekologie bespreek en illustreer het, kom D. Edwards tot die slotsom dat basiese plantekologiese navorsing benodig word, eerstens op streeksvlak deur streeksgeorienteerde plantekologiese studies om die noodsaaklike plaaslike inligting te verskaf wat benodig word deur navorsers, beplanners en persone wat die land gebruik; en tweedens in meer besonderhede waar kennis benodig word van die prosesse en faktore wat die gedrag van plantegroei beheer sodat dit behoorlik gebruik, bestuur en manipuleer kan word.

M. J. Wells bespreek die rol van ekonomiese plantkundiges om voorkeure in navorsing te bepaal, en om navorsing te doen op probleemplante soos onkruide, en op plante vir voedsel en ander nuttige produkte, veral van die ryk en onontginde Suid-Afrikaanse flora van meer as 17000 soorte. Die behoefte aan'n voldoende basis van primêre plantkundige gegewens word beklemtoon, asook aan etnobotaniese werk om as hulpmiddel te dien by navorsing oor plantgebruike.

S. A. Hulme, in sy opsomming vir die landboukundige sektor, wys daarop dat, ten spyte van die ontstaan van gespesialiseerde landbourigtings, plantkundige navorsing steeds fundamenteel bly tot die begrip van di2 plant. Hoewel plantkunde reeds belangrike bydraes gemaak het tot landbou, wag daar nog vele belangrike bydraes tot landbou in die toekoms deur fisiologiese en ander plantkundige studies.

In sy opsomming vir die nie-landboukundige sektor, illustreer $D$. M. Joubert die maniere waardeur die invloed van die Navorsingsinstituut vir Plantkunde, en sy samewerking met ander inrigtings en organisasies tot buite die landboukundige gebied strek, tot ander nasionale programme met betrekking tot droëland-en binnelandse waterekosisteme, in navorsing oor plantalkaloide, in natuurbewaring, e.d.m. 
